\title{
Brainstem Steering of Locomotor Activity in the Newborn Rat
}

\author{
Zied Oueghlani, Cyril Simonnet, Laura Cardoit, Gilles Courtand, Jean-René Cazalets, Didier Morin, Laurent Juvin,* \\ and $\mathbb{Q}$ Grégory Barrière* \\ Institut de Neurosciences Cognitives et Intégratives d'Aquitaine, Unité Mixte de Recherche 5287, Centre National de la Recherche Scientifique, Université \\ de Bordeaux, 33076 Bordeaux, France
}

Control of locomotion relies on motor loops conveying modulatory signals between brainstem and spinal motor circuits. We investigated the steering control of the brainstem reticular formation over the spinal locomotor networks using isolated brainstem-spinal cord preparations of male and female neonatal rats. First, we performed patch-clamp recordings of identified reticulospinal cells during episodes of fictive locomotion. This revealed that a spinal ascending phasic modulation of reticulospinal cell activity is already present at birth. Half of the cells exhibited tonic firing during locomotion, while the other half emitted phasic discharges of action potentials phase locked to ongoing activity. We next showed that mimicking the phasic activity of reticulospinal neurons by applying patterned electrical stimulation bilaterally at the ventral caudal medulla level triggered fictive locomotion efficiently. Moreover, the brainstem stimuliinduced locomotor rhythm was entrained in a one-to-one coupling over a range of cycle periods ( $2-6 \mathrm{~s})$. Additionally, we induced turning like motor outputs by either increasing or decreasing the relative duration of the stimulation trains on one side of the brainstem compared to the other. The ability of the patterned descending command to control the locomotor output depended on the functional integrity of ventral reticulospinal pathways and the involvement of local spinal central pattern generator circuitry. Altogether, this study provides a mechanism by which brainstem reticulospinal neurons relay steering and speed commands to the spinal locomotor networks.

Keywords: brainstem; CPG; descending control; locomotion; neonatal rat; spinal cord

\section{Significance Statement}

Locomotor function allows the survival of most animal species while sustaining the expression of fundamental behaviors. Locomotor activities adapt from moment to moment to behavioral and environmental changes. We show that the brainstem can control the spinal locomotor network outputs through phasic descending commands that alternate bilaterally. Manipulating the periodicity and/or the relative durations of the left and right descending commands at the brainstem level is efficient to set the locomotor speed and sustain directional changes.

\section{Introduction}

Locomotion is one of the essential functions for animal survival. Located within the cervical and lumbar regions of the spinal cord, the central pattern generators (CPGs) for locomotion (Cazalets et

Received April 27, 2018; revised July 17, 2018; accepted July 18, 2018.

Author contributions: Z.O. wrote the first draft of the paper; J.-R.C., D.M., L.J., and G.B. edited the paper; Z.O., L.J., and G.B. designed research; Z.O., C.S., L.C., G.C., L.J., and G.B. performed research; Z.O., J.-R.C., D.M., L.J., and G.B. analyzed data; L.J. and G.B. wrote the paper.

We are very grateful to John Simmers for his constructive comments on this manuscript and its editing. We also thank Anne Fayoux for management of the animal facility. Z.0. was supported by a doctoral studentship from the French "Ministère de l'Enseignement Supérieur et de la Recherche".

*L.J. and G.B. contributed equally to this work.

The authors declare no competing financial interests.

Correspondence should be addressed to either G. Barrière and L. Juvin at the above address, E-mail: gregory.barriere@u-bordeaux.fr or laurent.juvin@u-bordeaux.fr.

DOI:10.1523/JNEUROSCI.1074-18.2018

Copyright $\odot 2018$ the authors $\quad 0270-6474 / 18 / 387725-16 \$ 15.00 / 0$ al., 1995; Marcoux and Rossignol, 2000; Ballion et al., 2001; Barthélemy et al., 2007) organize the rhythmical activation of motoneuronal populations that innervate axial and limb muscles according to specific gait pattern requirements. These CPG circuits are under the direct control of supraspinal centers (from the cortex to brainstem) that are involved in the motivational aspect of locomotor behavior and the selection and modulation (direction change, speed, etc.) of the underlying motor output programs (Armstrong, 1986; Rossignol, 1996; Jordan et al., 2008).

Among these brainstem centers, the pontomedullary reticular formation is critical for the expression of adaptive locomotor behavior. This formation integrates locomotor-related information converging from the motor cortex, the mesencephalic locomotor region (MLR), the cerebellum, the hypothalamus, and the spinal sensorimotor networks, and thereby acts as a central hub for locomotor control (Matsuyama and Drew, 1997; Jordan, 1998; Matsuyama et al., 2004; Saitoh et al., 2007; Antri et al., 
2009). Reticulospinal output pathways, which are already functional at birth in the rat (Magnuson and Trinder, 1997), lie within the ventrolateral funiculi (VLFs; Steeves and Jordan, 1980; Noga et al., 1991, 2003) of the spinal cord, and contact both interneurons that may be part of the spinal locomotor CPGs and motoneurons (Jankowska et al., 2005; Hammar et al., 2007; Szokol et al., 2008, 2011; Szokol and Perreault, 2009).

In accordance with pioneering work showing that locomotion can be generated by tonic electrical stimulation of the upstream MLR in mammals (Shik et al., 1966; Garcia-Rill et al., 1987), tonic electrical stimulation of the reticular formation has been found also to trigger episodes of locomotion in vivo and in vitro (McClellan and Grillner, 1984; Garcia-Rill and Skinner, 1987; Atsuta et al., 1990; Noga et al., 1991). In both structures, the locomotor cycle frequency is correlated to the intensity or frequency of the stimulus trains. During locomotion, however, only a subpopulation of reticulospinal neurons (RSNs) actually discharge tonically, whereas a substantial proportion exhibits phasic discharges of action potentials phase locked to ongoing locomotor activity (Shimamura et al., 1982, 1985; Shimamura and Kogure, 1983; Drew et al., 1986; Kasicki and Grillner, 1986; Dubuc and Grillner, 1989; Kasicki et al., 1989; Perreault et al., 1993; Deliagina et al., 2000; Matsuyama and Drew, 2000). The phasic component of the reticulospinal activity provides the substrate for the gating of descending steering commands including turning instructions (Deliagina et al., 2000; Karayannidou et al., 2007; Kozlov et al., 2014).

Using the in vitro neonatal rat brainstem-spinal cord preparation, we aimed at mimicking the rhythmical activity of reticulospinal neurons observed during locomotion by applying alternating trains of electrical stimulation to the left and right surfaces of the ventral brainstem. We show first that most identified reticulospinal cells exhibit rhythmically modulated activity that is phasically coupled to locomotor output generated at the spinal cord level. Next, we show that patterned brainstem stimulation is highly effective in eliciting episodes of fictive locomotion. A major feature of such stimulation is that the cycle period of the evoked locomotor activity remains closely correlated to the period at which the patterned stimulation is applied. Furthermore, incorporating temporal asymmetries into the pattern of bilateral brainstem stimulation results in the generation of asymmetrical locomotor outputs. Finally, our data show that this dual brainstem stimulation method enables the production of motor patterns appropriate for turning behavior during ongoing episodes of pharmacologically induced locomotor activity. Thus, our results further underline the importance of the reticulospinal system in the flexible operation of downstream spinal locomotor networks and provide a novel technique for exploring the steering control of locomotion in quadrupeds.

\section{Materials and Methods}

Experiments were performed on in vitro isolated spinal cords from newborn Sprague Dawley rats $(n=91)$ of either sex aged from postnatal day 0 (P0) to P2. From these animals, 77 preparations successfully responded to our experimental protocols. All procedures were conducted in accordance with the local ethics committee of the University of Bordeaux and European Committee Council directives. All efforts were made to minimize animal suffering and the number of animals used.

In vitro isolated brainstem/spinal cord preparation. Rat pups were anesthetized with isoflurane until there was a lack of reflex response to tail and toe pinching. Each animal was decapitated, and the skin of the back was removed before positioning dorsal side up in a dissecting chamber. A laminectomy was performed to expose the brainstem and spinal cord, which were carefully dissected free using fine forceps and microscissors under binocular magnification. Dissections and recording procedures were performed under continuous superfusion of an artificial CSF (aCSF) equilibrated with $95 \% \mathrm{O}_{2}-5 \% \mathrm{CO}_{2}, \mathrm{pH} 7.4$, at room temperature $\left(24-26^{\circ} \mathrm{C}\right.$ ) and containing the following (in $\mathrm{mm}$ ): $130 \mathrm{NaCl}, 3 \mathrm{KCl}, 2.5$ $\mathrm{CaCl}_{2}, 1.3 \mathrm{MgSo}_{4}, 0.58 \mathrm{NaH}_{2} \mathrm{PO}_{4}, 25 \mathrm{NaHCO}_{3}$, and 10 glucose. In some experiments, the spinal cord was artificially partitioned using Vaseline walls, as previously described (Cazalets et al., 1995; Juvin et al., 2005), to restrict the bath application of pharmacological agents to specific spinal regions. The watertightness of the barriers was systematically checked at the end of the experiment by observing the movements of methylene blue added to the bathing medium on one side of the Vaseline walls.

Electrophysiological recordings and analyses. Motor activities were extracellularly recorded from lumbar ventral roots using Vaseline-insulated stainless-steel pin electrodes or suction electrodes. Extracellular activities were amplified $(10,000 \times$ ) by differential AC amplifiers (low cutoff, $100 \mathrm{~Hz}$; high cutoff, $1 \mathrm{kHz}$; model 1700, A-M Systems) and digitized using an A/D interface ( $2 \mathrm{kHz}, \mathrm{CED} 1401$, Cambridge Electronic Design) driven by Spike 2 software. The raw extracellular signals were high-passed $(50 \mathrm{~Hz})$, rectified, and integrated before analysis. Locomotor parameters were computed using custom-made routines written in MATLAB (MathWorks). Mean cycle parameter values were computed using an L2 ventral root as the reference because it invariably exhibited the best signal-to-noise ratio. Wavelet transform analyses (Mor and Lev-Tov, 2007) were performed using the MATLAB wavelet coherence package provided by A. Grinsted (http://noc.ac.uk/usingscience/crosswavelet-wavelet-coherence). A detailed explanation of the wavelet-based methodology used in the present work was presented previously by Mor and Lev-Tov (2007) (see also Torrence and Compo, 1998; Grinsted et al., 2004). This methodology enables access to the frequency content of the signal over time and extraction of the common power, correlation, and phase between pairs of simultaneously recorded signals from the cross-wavelet transform and wavelet coherence (Torrence and Compo, 1998; Grinsted et al., 2004). Raw extracellular signals were high-passed (50 $\mathrm{Hz}$ ), rectified, and smoothed. Each pretreated signal was decomposed in the frequency domain over time using a continuous wavelet transform (Morlet wavelet, 10 octaves per scale). Cross-wavelet and wavelet coherence algorithms were applied to paired, pretreated signals to highlight the common high power frequencies (color coded) and significant correlations (color coded) between each frequency component of signals over time. The changes in rhythmic activity frequencies and the coherence and phase relationships between signals were then extracted from regions of interest that were defined from mixed cross-coherence maps in which the results of the cross-wavelet and wavelet coherence were combined (Mor and Lev-Tov, 2007). For this purpose, each power value obtained in the time/frequency domain from the cross-wavelet transform was ponderated by the corresponding value of coherence (ranging from 0 to 1 ) obtained from the wavelet coherence. This allows highlighting of the time/frequency regions in which the two signals not only share common high power values but are also highly coherent.

Identified reticulospinal neurons were recorded intracellularly with patch-clamp (whole-cell configuration) using an Axoclamp 2B (Molecular Devices) and digitized at $10 \mathrm{kHz}$. Patch-clamp micropipettes (3-5 $\mathrm{M} \Omega$ ) were filled with a solution containing the following (in $\mathrm{mM}$ ): 120 K-gluconate, $0.1 \mathrm{CaCl}_{2}, 0.1 \mathrm{MgCl}_{2}, 1$ EGTA, $3 \mathrm{Na}_{2}$-ATP, 10 HEPES, 77 D-mannitol, 0.1 GTP, 0.2 cAMP, and 0.1 leupeptin, with $1 \%$ biocytin; $\mathrm{pH}$ was adjusted to 7.2 and the osmolarity to $306 \mathrm{mOsm}$. Reticulospinal neurons were identified by recording antidromic action potentials evoked by electrical stimulation of the ipsilateral ventrolateral funiculus at the midthoracic level (T8). Only neurons whose membrane potential could be maintained at a stable resting potential of $-60 \mathrm{mV}$ were considered.

Brainstem stimulation. Bilateral stimulation protocol was applied to the ventral surface of the brainstem using stainless-steel electrodes inserted into glass capillaries (GC150-10, Harvard Apparatus) filled with Ringer's solution. The size of the stimulating electrode tip was adjusted to $\sim 350 \mu \mathrm{m}$. Each stimulating electrode was associated with a stainlesssteel electrode for bipolar stimulation on each side of the brainstem. Trains of current or voltage pulses $(0.5-1 \mathrm{~ms}$ durations at $5 \mathrm{~Hz})$ were programmed with a Master-8 pulse generator (A.M.P.I.) connected to an ISO-Flex stimulus isolation unit (A.M.P.I.). 

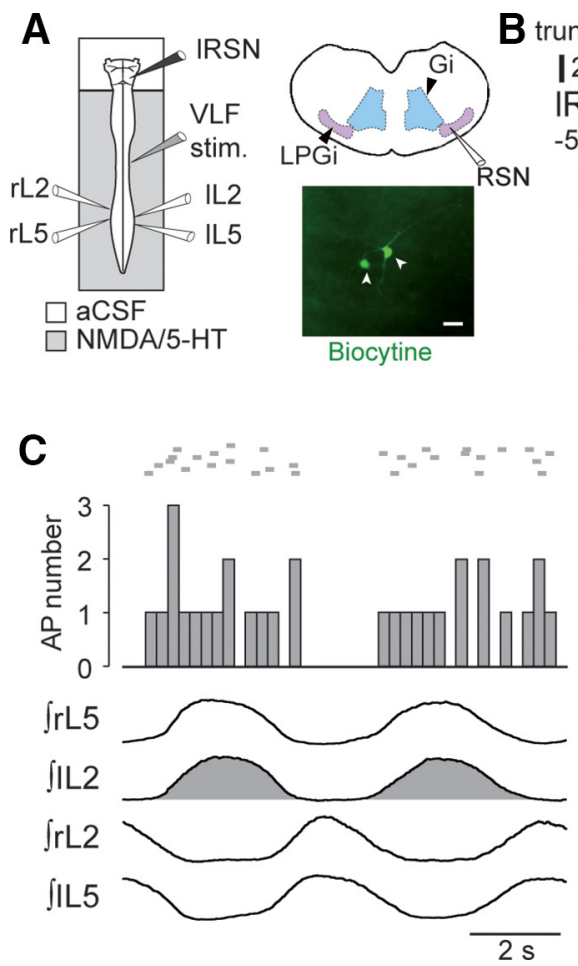

B truncated APa

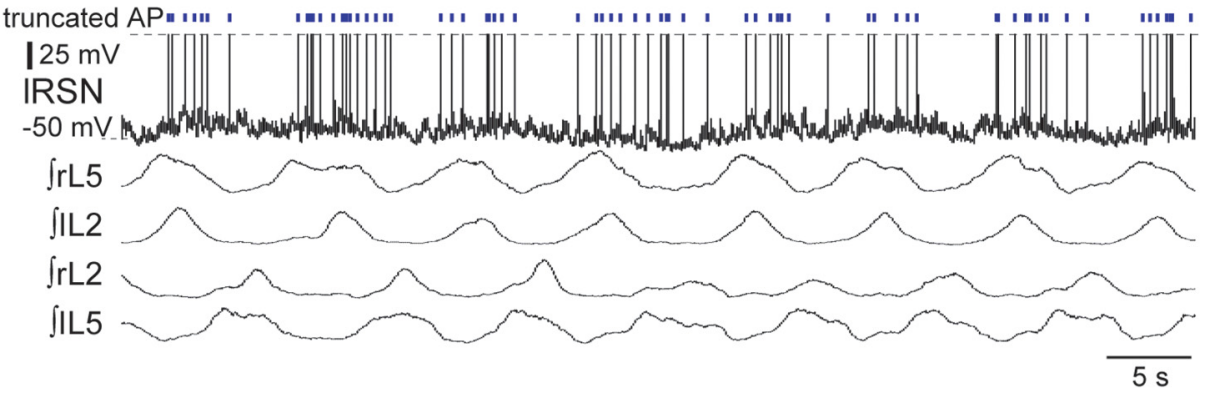

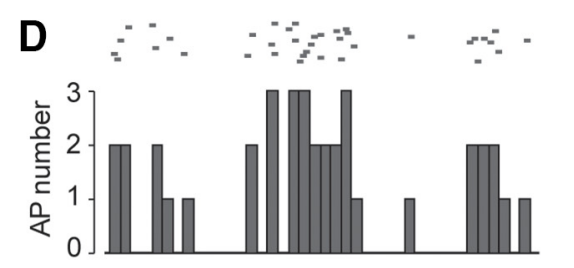

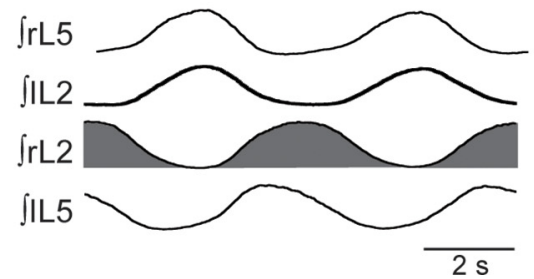

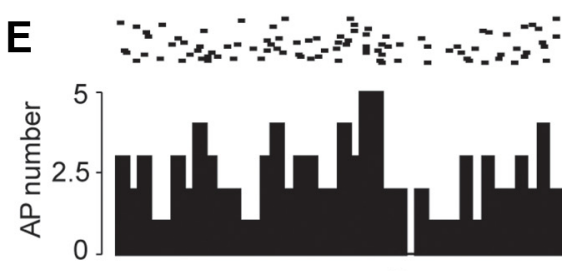

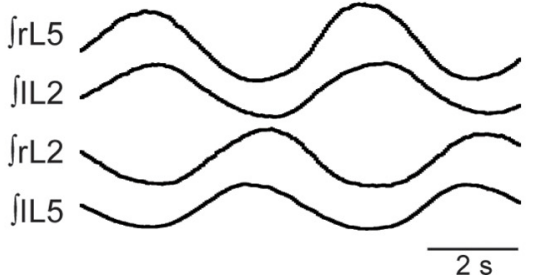

Figure 1. Discharge patterns of RSNs during fictive locomotion. $\boldsymbol{A}$, Left, Schematic of the isolated brainstem/spinal cord (ventral side up) and recording procedures. Right, Schematic coronal representation of the area where RSNs were recorded in the LPGi (top, purple shading) and two RSNs labeled with biocytin (bottom, white arrows, scale bar: $50 \mu \mathrm{m}$ ). $\boldsymbol{B}$, Whole-cell patch recording of an RSN (top trace) during an episode of pharmacologically induced fictive locomotion. The RSN's action potentials, which are truncated (dashed line), are indicated by vertical blue bars above the trace. Lower traces are integrated transforms of impulse activity recorded from rostral (bilateral L2) and caudal (bilateral L5) lumbar ventral roots. C-E, Raster plots (top) of spiking activity in three RSNs showing either phasic discharge in time with the left L2 ventral root ( $\boldsymbol{C}$, light gray) or right L2 ventral root ( $\boldsymbol{D}$, dark gray), or tonic discharge ( $\boldsymbol{E}$, black) during fictive locomotion. AP, action potential.

Pharmacology. In some experiments, episodes of locomotor-like activity were elicited by the exogenous bath application of a mixture of $7.5 \mu \mathrm{M}$ NMDA and $15 \mu \mathrm{M}$ serotonin (5-HT; Cazalets et al., 1992). All drugs were from Sigma. In another set of experiments, synaptic transmission was blocked reversibly in the upper lumbar segments. For this, the recording chamber was partitioned into three compartments with two Vaseline walls, and the intermediate lumbar cord compartment was perfused with a calcium-free aCSF, in which $\mathrm{CaCl} 2$ removal was compensated by an increase of $\mathrm{MgSO}_{4}$ concentration (3.79 mM).

Statistical analyses. Statistical analyses were performed on raw data with nonparametric tests using SigmaPlot 11 (Systat Software). A Kruskal-Wallis one-way ANOVA on ranks and Dunn's post hoc tests were carried out to test more than two groups. The level of significance was set at $p<0.05$. All data values are expressed as mean \pm SEM in the text and figures. In the latter, asterisks indicate positive significance levels, and numbers in or above histogram bars refer to the number of preparations tested. Circular statistics were performed using the Circular Statistic Toolbox in MATLAB (Berens, 2009).

\section{Results}

\section{Locomotor-related discharge pattern of} reticulospinal neurons

To first assess whether a phasic RSN activity is already present at birth in the rat (Orlovskiĭ, 1970; Dubuc and Grillner, 1989), we recorded intracellularly from identified RSNs in isolated newborn preparations during episodes of fictive locomotion monitored extracellularly in lumbar ventral roots (Fig. 1A). For this purpose, the in vitro brainstem/spinal cord was artificially partitioned at the high cervical level (C1-C2) with a Vaseline wall (Cazalets et al., 1995). This allowed the specific activation of spinal cord locomotor circuitry with NMDA $(7.5 \mu \mathrm{M})$ and 5-HT (15 $\mu \mathrm{M})$ while maintaining the brainstem under normal aCSF. All
RSNs were recorded on the left side of the ventral medulla and were identified by antidromic action potentials evoked by electrical stimulation of the left VLF at the midthoracic level. At rest, none of the 18 identified RSNs in this study expressed any firing activity. However, in 10 of 18 RSNs, pharmacological activation of the spinal locomotor network triggered the rhythmic firing of action potentials that were phase locked to the ongoing lumbar locomotor-like activity (Fig. 1B). Of these rhythmic cells, 5 fired impulses during the left flexor-like (L2) and concomitant right extensor-like (L5) motor bursts (Fig. 1C), while the remaining 5 rhythmic neurons discharged during the right flexor/left extensor bursts (Fig. 1D). Of the 8 remaining RSNs, activating the spinal locomotor network also triggered firing, but this activity remained tonic (Fig. 1E).

To locate the RSNs, which were blindly recorded in the present study, brainstem neurons projecting in the ventrolateral funiculus of the spinal cord were first retrogradely labeled unilaterally with dextran amine (Fig. 2A). The use of choline acetyltransferase (ChAT) immunostaining to provide landmarks (notably the nucleus ambiguus, dorsal motor nucleus of the vagus nerve, and hypoglossal nucleus) also allowed the mapping of reticulospinal neurons across the medullary formation and the $3 \mathrm{D}$ reconstruction of the corresponding reticular nuclei (Fig. $2 B-$ $D)$. Retrogradely labeled neurons were found in the gigantocellular reticular nucleus (Gi), the lateral paragigantocellular reticular nucleus (LPGi), the intermediate reticular nucleus (IRN), and the spinal trigeminal nucleus (Swanson, 1992; Paxinos and Ashwell, 2018). By then superimposing individual slices containing biocytin-labeled RSNs (Fig. 1A) onto those containing the VLF-projecting neurons, we found that the recorded 
A

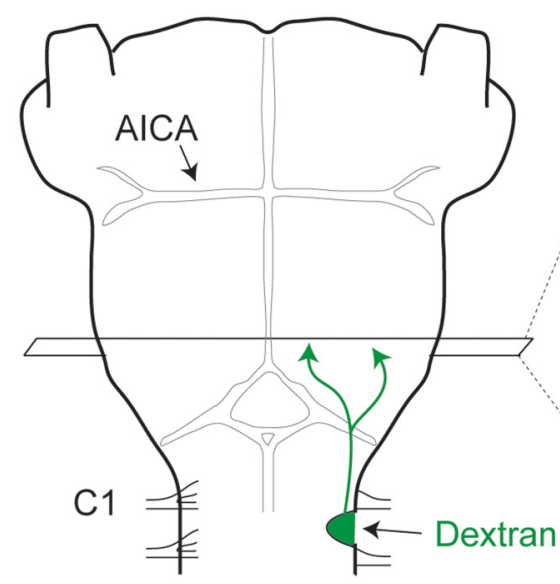

C

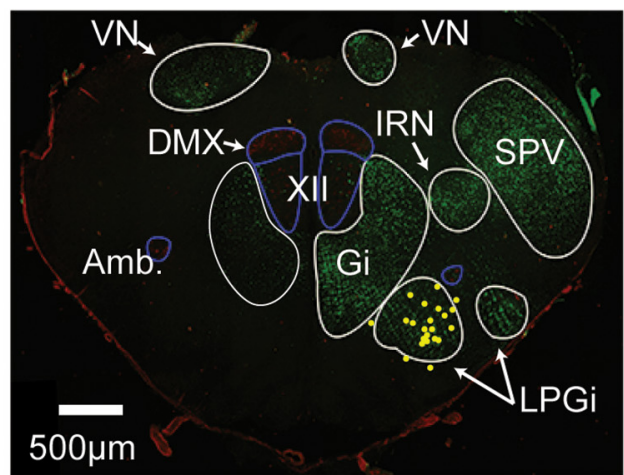

ChAT Recorded neurons Dextran
B

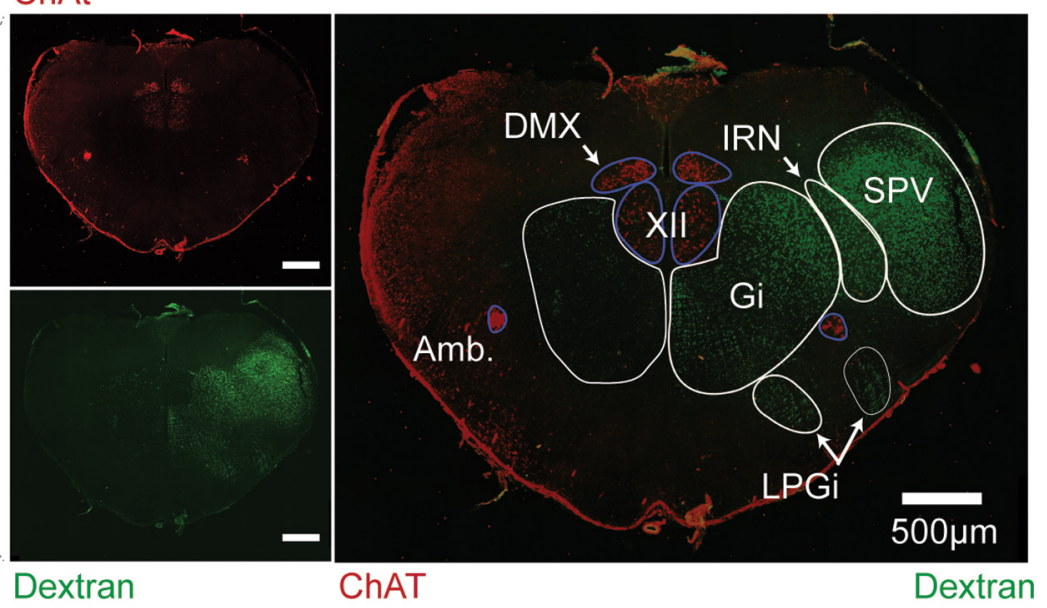

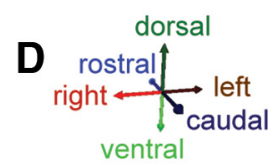

Figure 2. Localization of the spinally projecting neurons in the caudal brainstem. $A$, Labeling neurons projecting to the spinal cord by inserting dextran amine crystal into the upper cervical spinal cord. $\boldsymbol{B}$, Left, ChAT-labeled and dextran amine backfilled bulbar neurons shown in red (top) and green (bottom) respectively, in a coronal section of the caudal medulla. Right, Merged image at higher magnification showing the locations of the different bulbar neurons shown in red (top, scale bar: $500 \mu \mathrm{m}$ ) and green(bottom, scale bar: $500 \mu \mathrm{m}$ ). $\mathbf{C}$, Same representation as in B for a more rostral $(330 \mu \mathrm{m})$ section in the same plane. D, Three-dimensional representation of medullary nuclei; the LPGi and Gi are shaded in red and yellow respectively. AICA, Anterior inferior cerebellar artery; Amb., nucleus ambiguous; C1, first cervical spinal segment; DMX, dorsal motor vagal nucleus; SPV, spinal trigeminal nucleus; VN, vestibular nucleus; XII, hypoglossal nucleus.

RSNs were all located in the LPGi (Fig. 2C). Altogether, these data provide strong evidence that RSNs, at least those in the LPGi, already receive ascending locomotor-related information from the spinal cord CPGs at birth.

\section{Bilateral alternating brainstem stimulation induces fictive locomotion}

Tonic stimulation of the ventral surface of the medulla is well known to trigger episodes of fictive locomotion expressed by the spinal CPGs (Zaporozhets et al., 2004), which is characterized by alternating lumbar ventral root bursting that may persist after the brainstem stimulation ceases. In light of the rhythmic discharge observed in a subgroup of RSNs during fictive locomotion (see previous Results section), we asked whether a bilateral pattern of RSN/descending pathway activation resulting from repetitive trains of stimulation (stimulus frequency $5 \mathrm{~Hz}$ with individual train durations of $2 \mathrm{~s}$ ) delivered in strict alternation to the left and right sides of the ventral medulla might also be capable of activating the downstream spinal locomotor networks (Fig. 3A,B). Such a medullary rhythmic stimulation protocol (RSP) was indeed found to be highly effective in triggering episodes of lumbar ventral root motor bursting that fulfilled all the criteria of being locomotor-related activity as characterized by continuous wave- let-based methodology (Fig. 3C). Such analysis (Mor and LevTov, 2007; Beliez et al., 2015) allows extraction of the frequency of the cyclic motor activity and the phase relationships between pairs of recorded ventral roots. In the experiment of Figure 3, for example, the frequency of the rhythmic discharge $(0.25 \pm 0.01$ $\mathrm{Hz}$ ) was above $0.2 \mathrm{~Hz}$ (i.e., cycle period of $<5 \mathrm{~s}$ ), and the overall motor pattern expressed by individual preparations consisted of a bilateral alternation of homologous left/right bursts in the same lumbar segment [left L2 (lL2) vs right L2 (rL2), $170.3 \pm 4.1^{\circ}, n=$ 10 preparations] and of homolateral flexor (L2) and extensor (L5) bursts (rL5 vs rL2, $169.2 \pm 9.3^{\circ}, n=10$ preparations), as illustrated for one preparation in Figure $3 D$. In all cases observed, the left L2 (flexor-like) and right L5 (extensor-like) bursts of activity occurred exclusively in time with each stimulus train applied to the left ventral medulla (Fig. $3 E, F$ ). Conversely, the right L2 and left L5 motor bursts were time locked to the stimulus trains applied on the right ventral medulla.

Moreover, restricting the periodic brainstem stimulation to a single side only was ineffective in triggering locomotor-like activity ( $n=3$ preparations; data not shown), while stimulating the two sides of the brainstem concomitantly could only occasionally activate the spinal locomotor network (in $n=2$ of 4 preparations; data not shown). In addition, our stimulus paradigm was effi- 
A
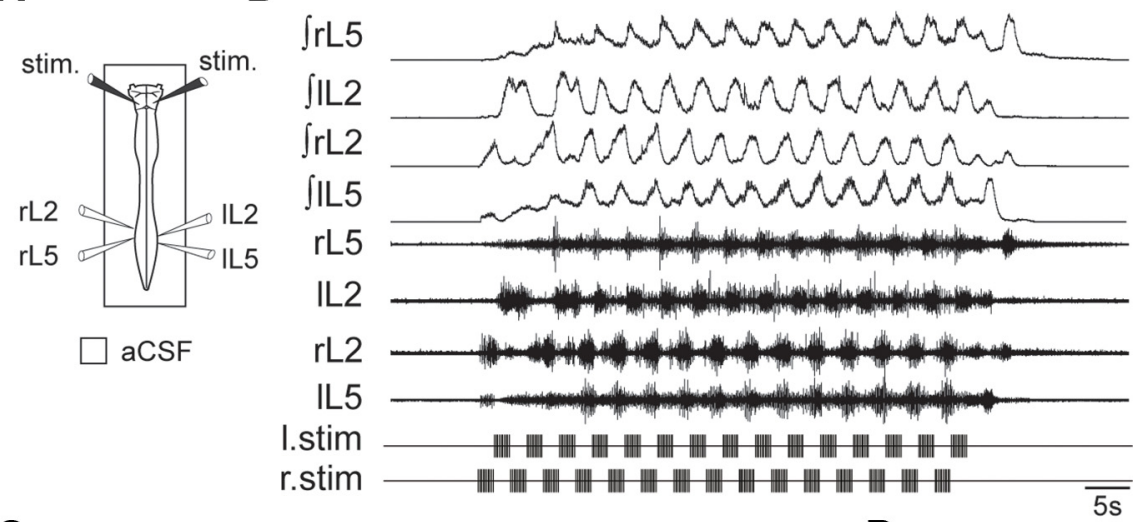

C

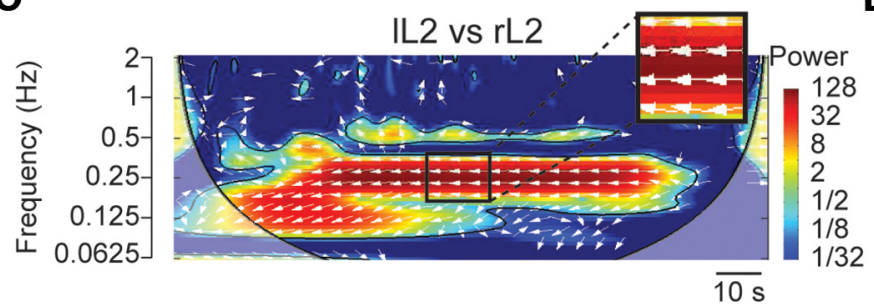

D
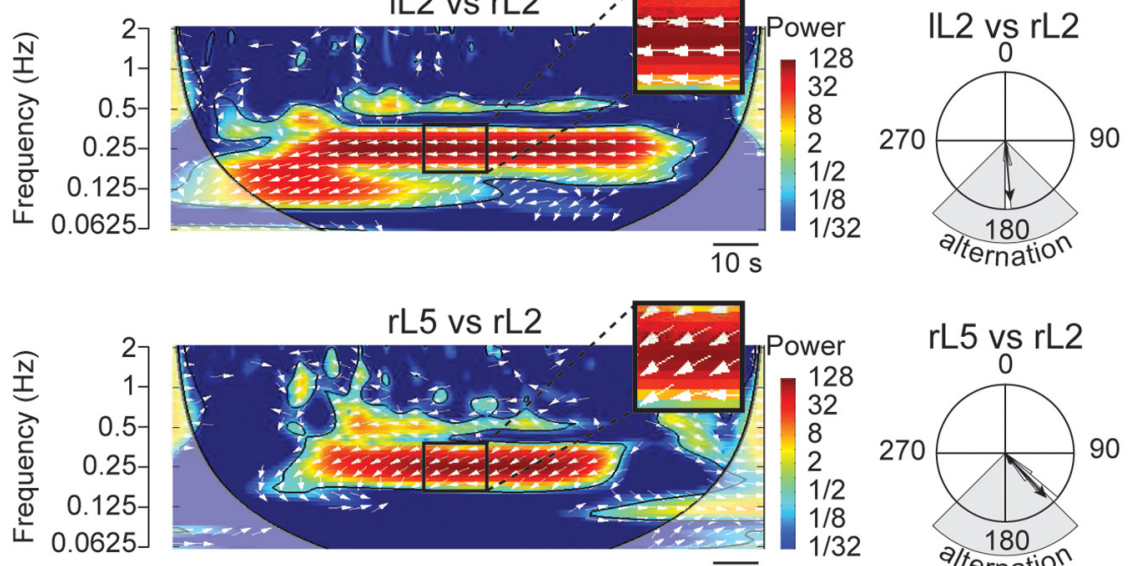

rL5 vs rL2

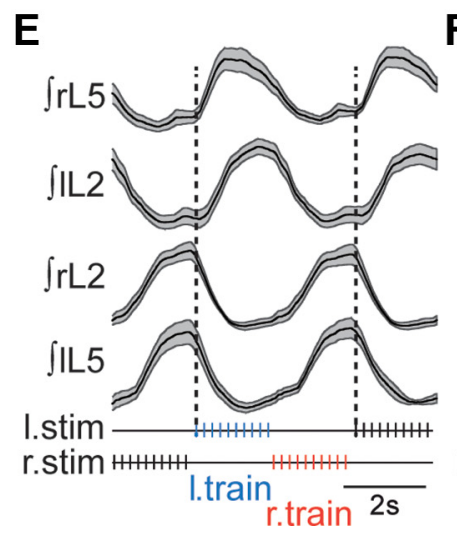

$F$

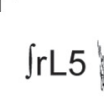

$\int \mathrm{IL} 2$

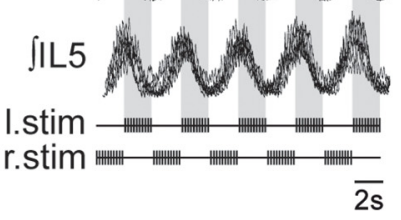

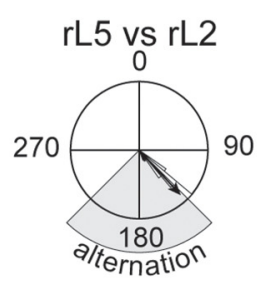

G

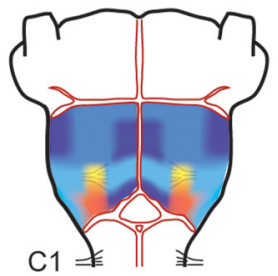

Score (\%)

0255075100

Figure 3. Fictive locomotion induced by alternating bilateral brainstem stimulation. $A$, Schematic of experimental procedure. $\boldsymbol{B}$, Raw (bottom) and integrated (top) activities of $L 2$ and $L 5$ ventral roots during an episode of fictive locomotion induced by an RSP consisting of alternating left-right train stimulation to the ventral surface of the caudal medulla. $\boldsymbol{C}$, The wavelet cross-coherence maps show the relationship between bilateral L2 (IL2 vs rL2; top) and ipsilateral lumbar (rL5 vs rL2; bottom) ventral root activities illustrated in $\boldsymbol{B}$ (high coherence values are indicated in red). $\boldsymbol{D}$, Circular plot analysis of the same recordings showed phase alternation between bilateral L2 (top) and homolateral lumbar root (bottom) activities. $\boldsymbol{E}$, Integrated mean activity of the lumbar ventral roots (black trace) during the same recording as in $\boldsymbol{B}$. The variability over time of lumbar locomotor-related bursts is indicated by the SEM (gray shaded area). $\boldsymbol{F}$, Overlay of recordings from seven different preparations during episodes of fictive locomotion. The vertical gray shaded bars indicate the stimulation duration for the left medulla. $\boldsymbol{G}$, Color-coded representation of the ventral brainstem indicating the percentage of preparations [Score (\%)] displaying locomotor-like activity when stimulated bilaterally in each area. Colors ranging from blue to red correspond to low to high scores as follows: dark blue $(0$ of $7,0 \%)$; mid-dark blue (1 of 7, 14.3\%); light blue (2 of 7, 28.6\%); yellow (4 of 7, 57.1\%); dark orange (6 of 7, 87.7\%).

cient uniquely when applied to a relatively restricted area of the ventral medulla, as was evident in experiments where the ventral medulla was subjected to RSP at different locations across its surface. As indicated in the heat map diagram in Figure $3 G$, which summarizes the results obtained from seven preparations tested, symmetrical bilateral stimulation of the caudal intermediolateral region of the brainstem was particularly effective in inducing spinal locomotor-like activities (red areas). In contrast, stimulating neighboring sites was effective only in some preparations (yellow areas), while at more distant sites, RSP application could at most occasionally trigger tonic activity at the lumbar level (blue areas). Consequently, specific patterned stimulation of the caudoventral intermediolateral medulla, an area encompassing the LPGi, provides a potent method for activating the spinal locomotor network and sustaining its expression throughout stimulation.

\section{RSP-mediated control of locomotor cycle period}

It was shown previously that the cycle period of fictive locomotor outputs obtained from the in vitro neonatal rat spinal cord in response to tonic brainstem stimulation can be modulated, albeit over a limited range, by manipulating the stimulus amplitude or frequency (Zaporozhets et al., 2004). However, we found that increasing either the frequency or amplitude of the stimuli within each train using RSP did not modulate the locomotor cycle period ( $n=5$ preparations; data not shown). In contrast, the locomotor output period was strongly governed by the period of the applied stimulation pattern, at least in a range of 2 to $6 \mathrm{~s}$. This is illustrated in Figure 4 for a typical preparation to which the RSP was applied using different train stimulation periods. It should be noted that during such trials, the total number of individual stimuli delivered per stimulus sequence was held constant. Thus, increasing the cycle period (and the duration of the bilaterally symmetrical, $50 \%$ duty cycle trains) was associated with a corresponding increase in the stimulus intensity within individual trains.

When the RSP was applied at a period of $1 \mathrm{~s}$, locomotor-like activity immediately emerged during the early part of the stimulus episode (Fig. 4A), with a cycle period $(3.41 \pm 0.01 \mathrm{~s})$ that was visibly independent of the period of the patterned stimulation (Fig. 4B). Moreover, the rhythmic motor response could not be maintained for the entire duration of the stimulus sequence, and eventually ventral root activity became tonic (Fig. $4 A$ ). In contrast, a tight coupling between the locomotor and stimulation patterns was obtained when the latter's period was increased to $3 \mathrm{~s}$ (Fig. $4 C, D$ ) and then $5 \mathrm{~s}$ (Fig. $4 E, F$ ). In both cases, the cycle periods of RSP stimulation and of locomotor output $(3 \mathrm{~s}, 2.97 \pm$ 
$0.01 s ; 5 s, 4.98 \pm 0.01 s)$ were almost identical. Furthermore, these increased periods of stimulation were effective in maintaining locomotor network activation throughout the entire duration of stimulus application. In five preparations, where the RSP was applied at different periods of 1-6 s, the locomotor rhythm could be entrained in a one-to-one coupling over periods ranging from $3 \mathrm{~s}$ to almost 6 s (Fig. 4G,H).

\section{RSP-mediated control of the locomotor} pattern structure

As mentioned above, motor bursts recorded from the L2 ventral roots during RSP-driven entrainment were always phase locked to the ipsilateral stimulus trains. On this basis, we then tested in 10 preparations the effect of an asymmetrical manipulation of the train durations applied to each side of the brainstem. In the representative example illustrated in Figure $5 A$, the durations of the stimulus trains applied to the left and right sides were set to 3 and $1 \mathrm{~s}$, respectively (i.e., with left-biased asymmetry), with a stimulus cycle period of $4 \mathrm{~s}$. Under this asymmetric condition, the brainstem stimulation was still effective in triggering, sustaining, and entraining episodes of lumbar locomotor output (Fig. 5A). However, in contrast to the symmetrical paradigm applied previously to the same preparation (Fig. $5 B$ ), an asymmetric RSP led to asymmetrical patterns of fictive locomotion (Fig. 5C,D). When the stimulus paradigm was biased toward the left side so that train durations were increased and decreased on the left and right sides, respectively, the durations of the left L2 motor bursts increased, while they decreased on the right side (Fig. 5C). Moreover, the flexor-like (L2) burst phases on one side remained synchronous with the extensor-like (L5) phases on the opposite side, with increased and decreased L5 burst durations occurring on the right and left sides, respectively. Conversely, when the RSP was biased toward the right side (Fig. 5D), the right L2 and left L5 burst durations increased, whereas the left L2 and right L5 durations decreased.

The histograms of Figure $5 E$ summarize the results obtained from all 10 preparations in which an asymmetrical RSP was tested. Locomotor burst durations were altered with the asymmetric RSP compared to those expressed with the symmetrical paradigm, but without any change in motor cycle period, which remained fixed to the stimulation period (symmetrical, $3.98 \pm$ $0.03 \mathrm{~s}$; asymmetrical, left bias, $3.99 \pm 0.01 \mathrm{~s}$; asymmetrical, right bias, $4.04 \pm 0.05 s ; H_{(2,18)}=0.251 ; p=0.88$, ANOVA on ranks). However, the duration of the motor bursts on the more weakly stimulated side, involving either synergistic rL2 and lL5 (Fig. $5 C$ ) or IL2 and rL5 (D), were generally longer than the corresponding stimulus trains. In addition, the phase relationships between the
A

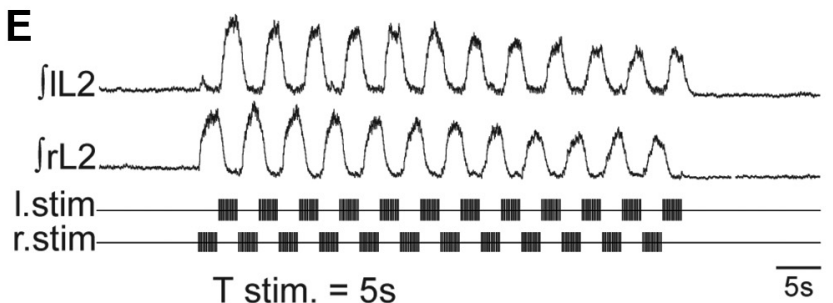

B
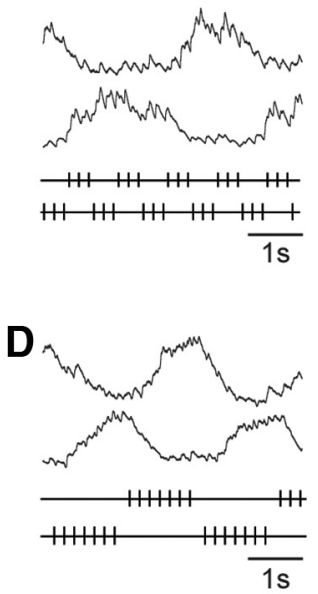

$\mathbf{F}$

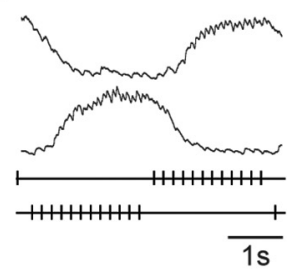

G

Figure 4. Control of the locomotor cycle period by RSP. $A, C, E$, Lumbar ventral root activities at different RSP periods of 1,3 , and $5 \mathrm{~s}$, respectively, in each case with an overall individual stimulus frequency of $5 \mathrm{~Hz}$. $\boldsymbol{B}, \boldsymbol{D}, \boldsymbol{F}$, Expanded segments confidence interval (C.I.; 95\%) for the mean; the dotted line indicates a theoretical linear one-to-one relationship. $\boldsymbol{H}$, Histogram illustrating the percentage of preparations $(n=5)$ entrained in a one-to-one manner by the RSP at the indicated train stimulus periods. T stim, period of the stimulation trains.

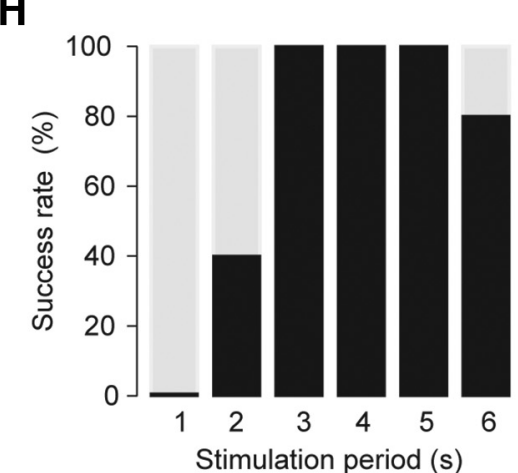

different motor outputs were affected in accordance with the bias paradigm of RSP stimulation. As is evident from the polar diagrams of Figure $5 F$, although the phase relationship between contralateral flexor (L2) and extensor-like (L5) bursts was not significantly modified by the asymmetrical condition (IL5 vs rL2, symmetrical, $6.2 \pm 7.2^{\circ}$; asymmetrical, left bias, $11.8 \pm 7.2^{\circ}$; asymmetrical, right bias, $21.4 \pm 18.0^{\circ} ; H_{(2,18)}=1.369 ; p=0.50$, ANOVA on ranks; Fig. $5 F$, left), the phase positions of bilateral homologous and homolateral motor bursts were altered relative to their phases in the symmetrical stimulus condition. Specifically, the phase values calculated between left and right L2 were significantly different (IL2 vs rL2, symmetrical, $170.2 \pm 4.1^{\circ}$; asymmetrical, left bias, $132.2 \pm 5.7^{\circ}$; asymmetrical, right bias, $209.7 \pm 5.9^{\circ} ; H_{(2,18)}=20.091 ; p<0.001$, ANOVA on ranks; Fig. 
A

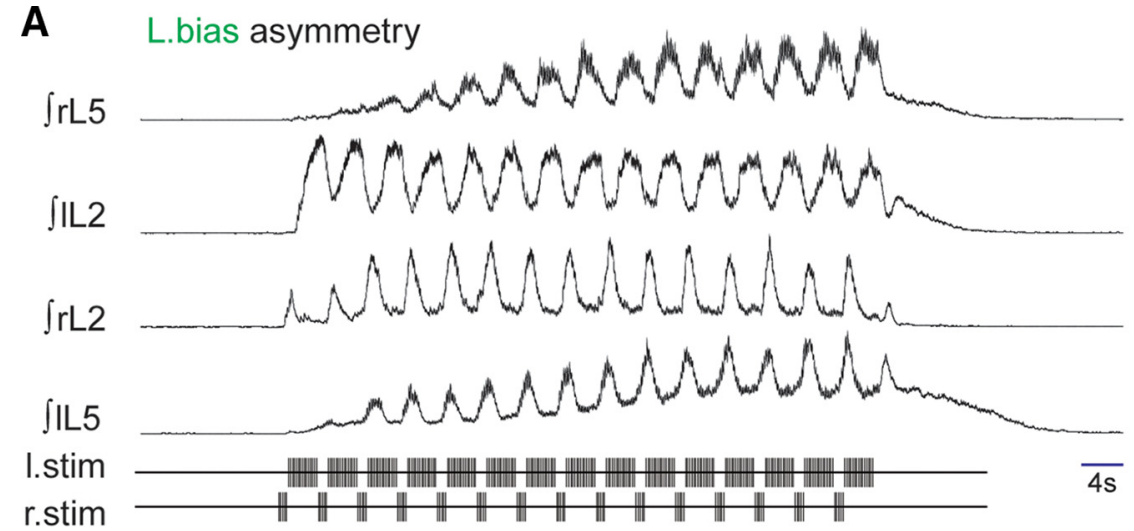

B
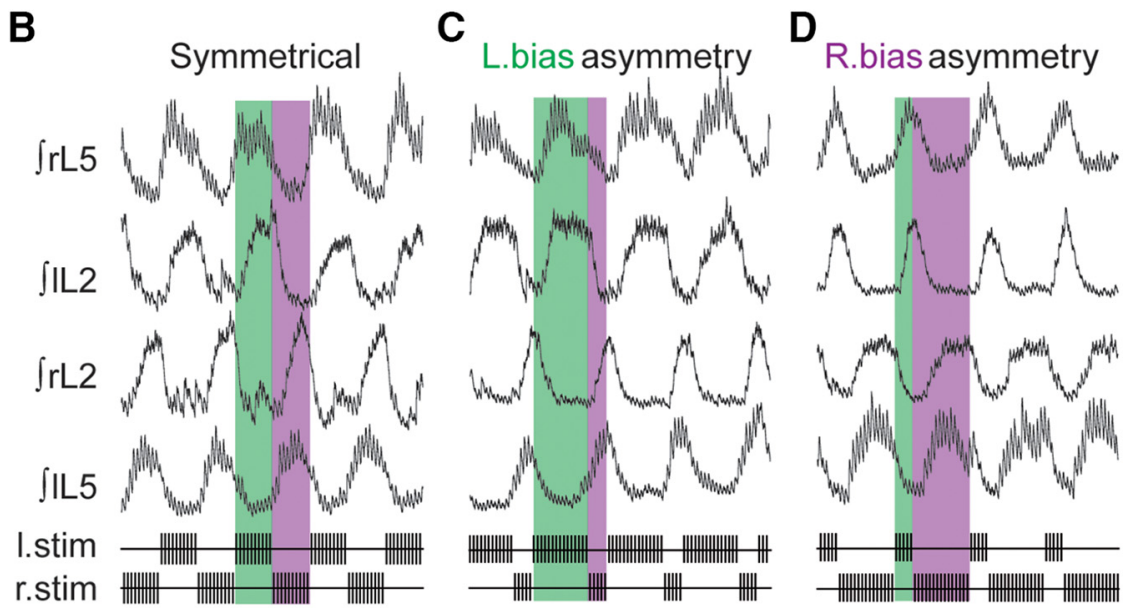

$\mathrm{E}$
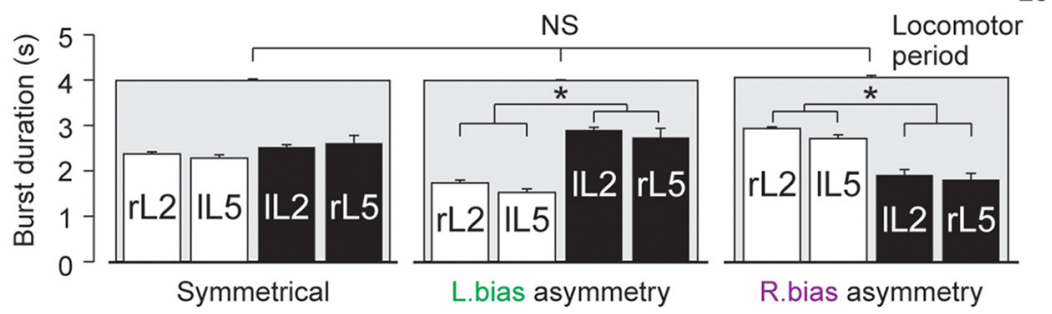

$\mathbf{F}$

IL5 vs rL2
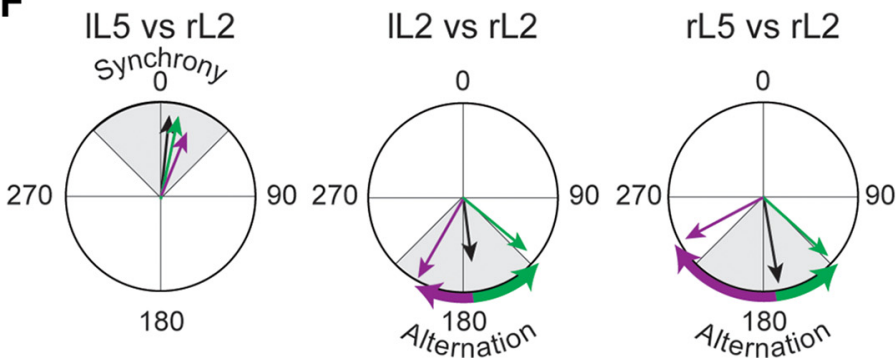

Figure 5. Left-right asymmetrical fictive locomotion induced by bilaterally asymmetrical stimulation protocols. $A$, Integrated activities of lumbar ventral roots (top traces) illustrating an episode of asymmetrical fictive locomotion induced by a left bias RSP (bottom traces). $\boldsymbol{B}-\boldsymbol{D}$, Expanded recording segments showing the temporal organization of the locomotor pattern resulting from symmetrical $(\boldsymbol{B})$, leftbiased ( $($, and right-biased (D) RSPs. The blue- and orange-shaded areas indicate the durations of the left and right stimulus trains, respectively. $\boldsymbol{E}$, Histograms showing the evolution of lumbar ventral root burst durations and cycle periods with symmetrical (left), leftbiased (middle), and right-biased (right) RSPs in 10 preparations (asterisks indicate $p<0.001$ ). $\boldsymbol{F}$, Circular plots of the phase relationships between the activities of ventral root pairs during symmetrical (black), left-biased (green), and right-biased (purple) RSPs.

$5 F$, middle), as were the values for right $\mathrm{L} 5$ and right $\mathrm{L} 2$ motor bursts (rL5 vs rL2, symmetrical, $170.9 \pm 17.4^{\circ}$; asymmetrical, left bias, $129.6 \pm 10.1^{\circ}$; asymmetrical, right bias, $242.0 \pm 9.7^{\circ} ; H_{(2,18)}=$ $12.406 ; p=0.002$, ANOVA on ranks; Fig. $5 F$, right). Thus, creat-
Symmetrical L.bias asym.

R.bias asym.

ing a temporal asymmetry between the left and right descending locomotor commands induced a set of phase shifts between the motor outputs that matched those that would be expected during a turning behavior (Deliagina et al., 2000; Fagerstedt and Ullén, 2001; Fagerstedt et al., 2001).

To test the flexibility of the temporal control of locomotion by RSP, we applied in three preparations a modified stimulation protocol during which the asymmetrical bias was reversed from the left to the right side. As illustrated in Figure $6 \mathrm{~A}$ for one preparation, when a left bias stimulation was switched to a right bias, the locomotor pattern of activity was swiftly reversed accordingly. Indeed, as the RSP was reversed, IL2 and rL2 mean burst durations were decreased and increased, respectively (lL2, from $2.65 \pm 0.07 \mathrm{~s}$ to $1.08 \pm 0.03 \mathrm{~s} ; \mathrm{rL2}$, from $0.99 \pm 0.04 \mathrm{~s}$ to $2.75 \pm 0.04 \mathrm{~s} ; n=3$ preparations; Fig. $6 B$ ). Concomitantly, the phase coupling between right and left L2 activities was shifted from $262.7 \pm 4.6^{\circ}$ to $99.8 \pm 2.7^{\circ}$ by the RSP switch ( $n=3$ preparations; Fig. 6C). This last observation reveals the versatility of RSP protocols for the steering control of the spinal locomotor networks.

\section{RSP effects on ongoing locomotor activity}

We next examined the effects of patterned brainstem stimulation during sequences of already activated locomotor-like activity. First, fictive locomotion was induced through bath application of a cocktail of NMDA $(7.5 \mu \mathrm{M})$ and 5-HT $(15 \mu \mathrm{M})$ that is classically used with this preparation (Fig. 7A; Cazalets et al., 1992). After locomotor activity had emerged and become stabilized, the RSP was then applied to the brainstem (Fig. $7 B$ ). In the example provided in Figure $7 B$, the RSP was composed of symmetrical left-right trains of stimulation with a period of $3 \mathrm{~s}$. Immediately with the onset of such stimulation, the locomotor period decreased and remained throughout the entire sequence to a value close to the $3 \mathrm{~s}$ stimulation period (before stimulation, $4.06 \pm 0.03 \mathrm{~s}$; during stimulation, $2.94 \pm 0.01 \mathrm{~s}$; Fig. 7C). At the termination of stimulation, the spontaneous rhythm paused transiently but rapidly resumed (within $10 \mathrm{~s}$ ), albeit with a longer cycle period $(5.13 \pm 0.03 \mathrm{~s})$ than before the stimulus sequence was applied. Significantly, also, the RSP could increase or decrease the period of ongoing fictive locomotion over a limited period range: when the RSP period exceeded the spontaneous motor period by $>50 \%$, the locomotor rhythm could no longer be entrained in a one-to-one manner $(n=11$; Fig. $7 D)$. 

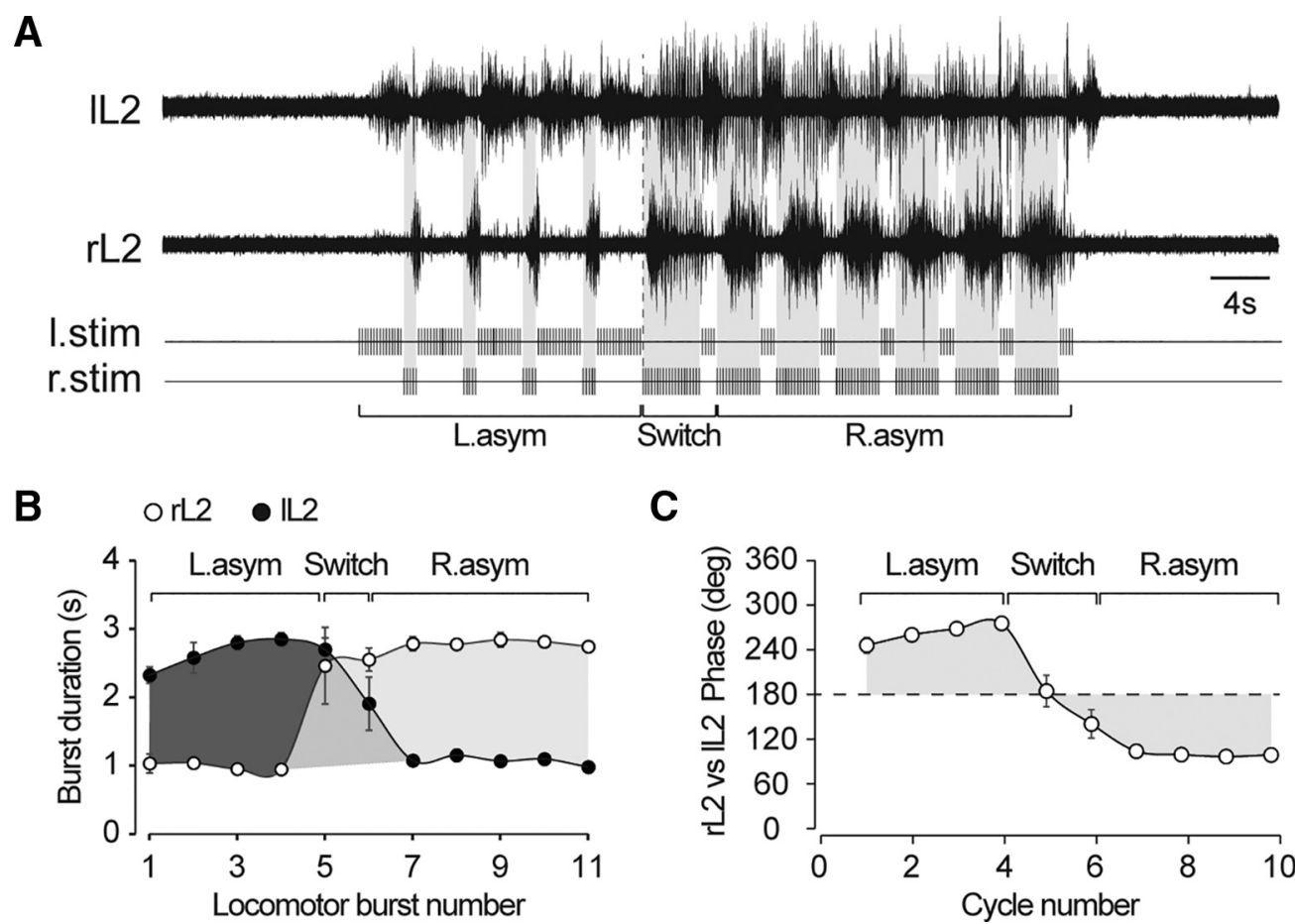

C

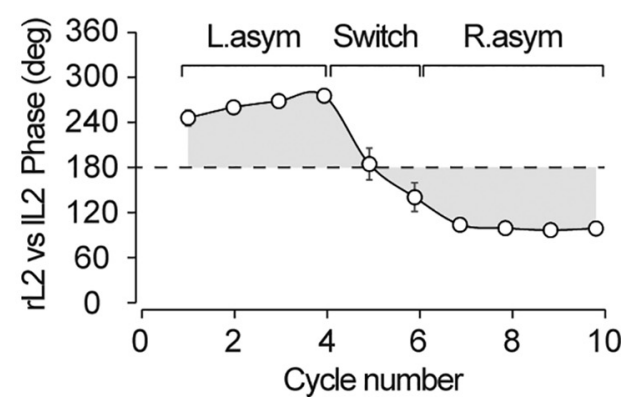

Figure 6. Versatile control of asymmetrical fictive locomotion by RSP. A, Raw ventral root activities during a sudden reversal of the asymmetrical RSP, switching from a left to a right bias. The vertical dotted line indicates the reversal time onset. $\boldsymbol{B}, \boldsymbol{C}$, Scatter plots showing the evolution of the mean burst durations $(\boldsymbol{B})$ and mean phase relationships $(\boldsymbol{C})$ obtained from three preparations exposed to the same imposed stimulation protocol as in $\boldsymbol{A}$. The horizontal dotted line at $180^{\circ}$ in $\boldsymbol{C}$ indicates a strict alternation between the ventral root activities.

The ongoing locomotor pattern could also be strongly influenced by the asymmetrical RSP. This is illustrated in the preparation of Figure $7 E$, where a left-biased RSP (i.e., longer left-side trains) was applied during a left/right symmetrical episode of pharmacologically induced locomotion. Upon initiation of the RSP, the locomotor pattern rapidly switched to a left/right asymmetrical pattern that corresponded to the temporal organization of the RSP, as indicated by the increase and decrease of the lL2 and rL2 motor bursts, respectively (lL2, from $1.97 \pm 0.04 \mathrm{~s}$ to $3.19 \pm 0.04 \mathrm{~s} ; \mathrm{rL2}$, from $1.84 \pm 0.05$ s to $1.50 \pm 0.03 \mathrm{~s}$; Fig. $7 F$ ). Concomitantly, the burst durations of L5 on one side remained correlated with those of their contralateral L2 counterpart (Fig. $7 E)$. Importantly, this reshaping action was superimposed on an entrainment-driven alteration in the locomotor output period that was increased to match the period of the RSP stimulation (from $2.74 \pm 0.08 \mathrm{~s}$ to $4.02 \pm 0.04 \mathrm{~s}$; Fig. $7 G$ ). On this basis, therefore, biasing the locomotor pattern through the RSP was achieved through a modulation of the phase relationship between the left and right L2 motor bursts that decreased to match the imposed stimulus pattern (from $187.4 \pm 5.8^{\circ}$ to $99.1 \pm 2.56^{\circ}$; Fig. $7 H$ ). Together, our results show the ability of the RSP applied to the brainstem to modulate the speed of locomotor burst activity as well as to define the left/right symmetry of burst durations and phase relationships.

\section{Spinal pathway mediating the RSP locomotor influence}

Although the effective stimulation area for the RSP in the caudal brainstem is likely to activate the medullary reticular formation and reticulospinal neurons, it may additionally activate pyramidal and serotonergic tracts that both project into the spinal cord level (Jordan et al., 2008). To distinguish the contribution of each of these pathways, we performed a series of experiments in which the RSP was applied following either dorsal or ventral spinal cord lesions (Fig. 8). All preparations used expressed a locomotor- related pattern in response to the symmetrical RSP before spinal section (Fig. $8 A-D$ ). Following a dorsal cord lesion that notably abolishes the passage of any descending pyramidal corticospinal information (Fig. $8 E, F$ ), six out of six preparations still expressed fictive locomotion that could be triggered and entrained by the RSP (Fig. 8G), with typical bilateral and flexor/extensor alternations (Fig. $8 \mathrm{H}$ ). Thus, although the RSP might activate components of the pyramidal tract, the latter is not critical to the former's effects on locomotor pattern production. On the other hand, following a ventral spinal cord lesion that removes descending inputs from the reticular formation (Fig. $8 I, J$ ), RSP was no longer able to trigger fictive locomotion in any of the six preparations tested (Fig. $8 \mathrm{~K}$ ). Together, therefore, these results indicate that the ventral/ventrolateral pathways are responsible for mediating the RSP's activating influence on spinal locomotor circuitry.

The caudoventral brainstem area is composed of reticulospinal glutamatergic neurons (notably, from the LPGi) but contains also serotonergic neurons (Liu and Wong-Riley, 2010), which are known to descend in the spinal cord and activate the spinal CPG (Liu and Jordan, 2005). To assess for a possible contribution of serotonergic neuronal populations to RSP-induced locomotorlike activity, we subjected eight standard in vitro preparations (Fig. 9A) that showed a typical locomotor response to RSP (Fig. $9 B, C)$ to stimulation in the presence of antagonists of the serotonergic 5- $\mathrm{HT}_{2 \mathrm{~A}}$ (ketanserin, $10 \mu \mathrm{M}$ ) and 5- $\mathrm{HT}_{7}$ (SB269970, 10 $\mu \mathrm{M})$ receptors, which are both known to mediate serotonininduced locomotor activity at the spinal cord level (Pearlstein et al., 2005; Cabaj et al., 2017; Fig. 9D). Under this condition, rhythmical burst activity could still be obtained in six of eight preparations, as illustrated in Figure 9E, which is from the same preparation as in Figure 9B, and the same pattern of burst alternations was observed in comparison with the control condition (Fig. 9C,F). Consequently, these findings support the conclusion 


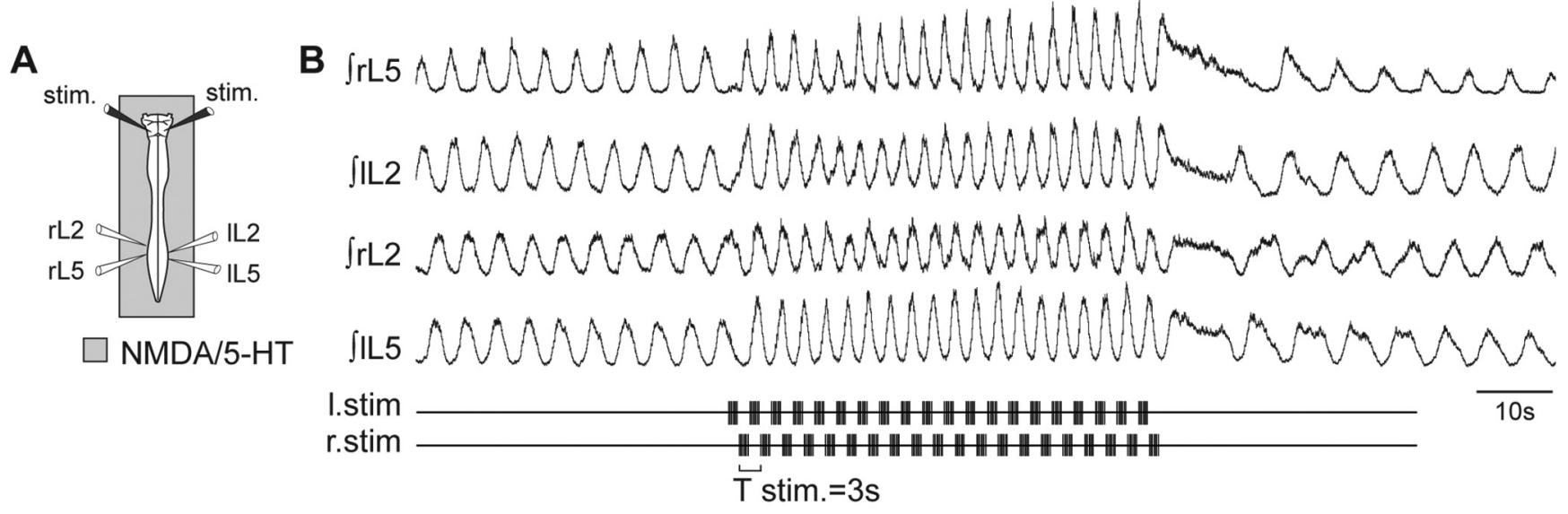

C

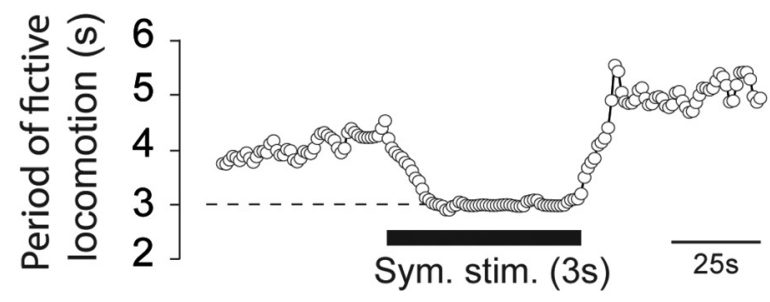

$\mathbf{E}$

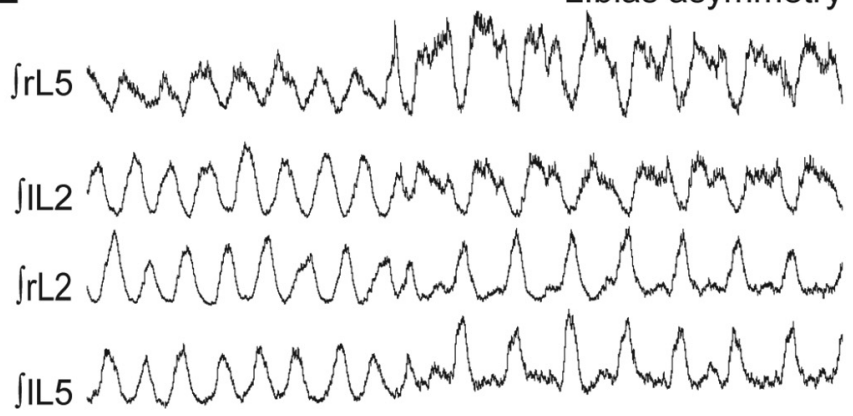

I.stim

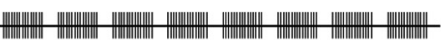

r.stim

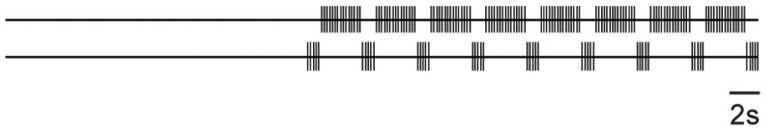

G

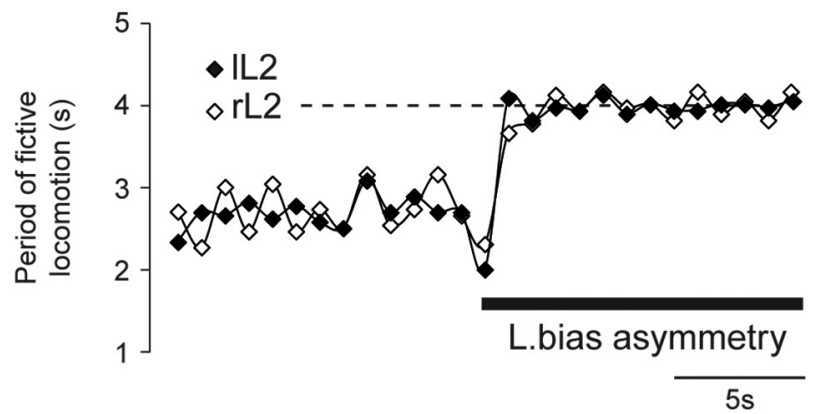

D $\quad$ entrained prep. - non-entrained prep.

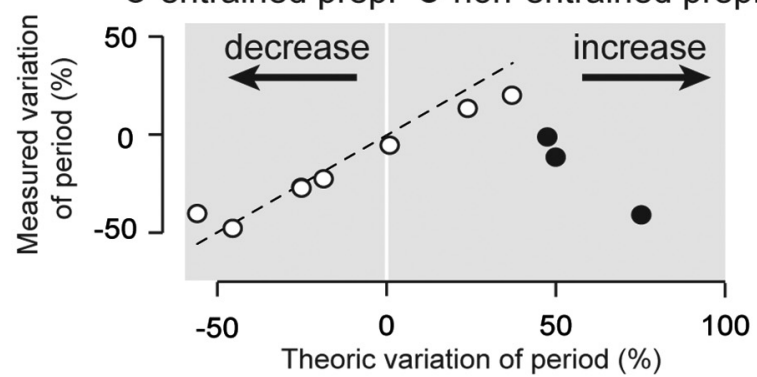

$\mathbf{F}$

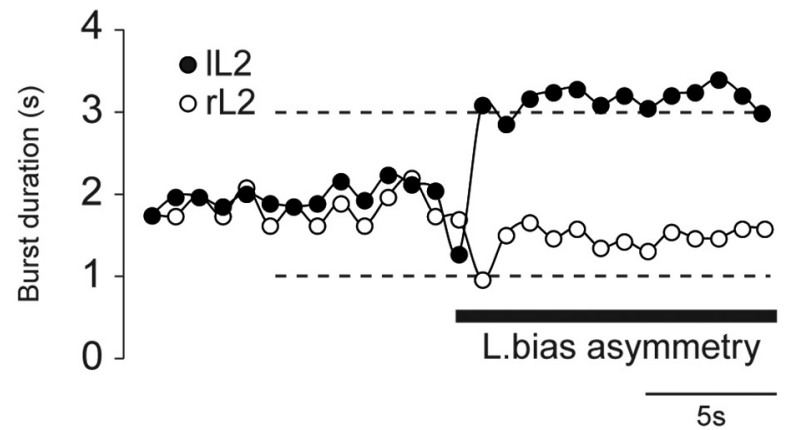

H

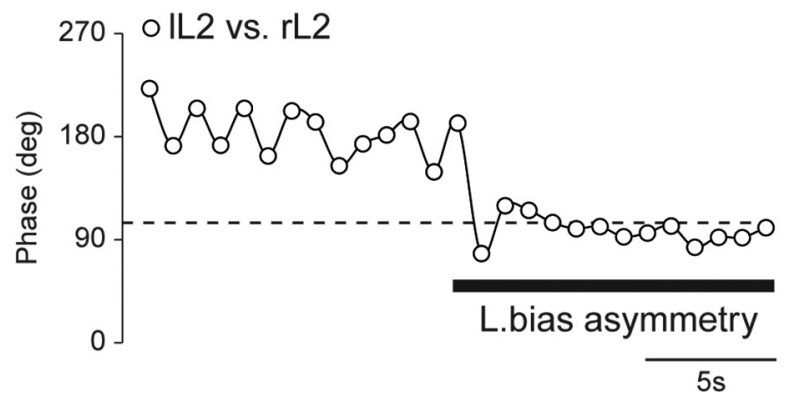

Figure 7. Control of fictive locomotor steering by RSP. $A$, Schematic of experimental procedure. $B$, Integrated activities of lumbar ventral roots illustrating an episode of fictive locomotion induced pharmacologically (NMDA/5-HT) during which a symmetrical RSP is applied to the ventral surface of the caudal medulla. C, Scatter plot showing the evolution of the cycle period of lumbar motor bursts during the same recording. The dashed line indicates the period of the stimulus trains. D, Scatter plot showing the percentage range of RSP periods over which the locomotor cycle period could be entrained in a one-to-one manner (dashed line). $\boldsymbol{E}$, Integrated activities of lumbar ventral roots illustrating an episode of fictive locomotion induced pharmacologically during which a left-biased RSP was applied. $\boldsymbol{F}$, Scatter plot showing the evolution of lumbar ventral root burst durations during the same recording. The dashed lines indicate the durations of the left-right RSP trains. $\mathbf{G}, \boldsymbol{H}$, Same representations as in $\boldsymbol{F}$ illustrating the evolution of ventral root cycle periods $(\boldsymbol{G})$ and phase relationships $(\boldsymbol{H})$. T stim, period of the stimulation trains. 
A
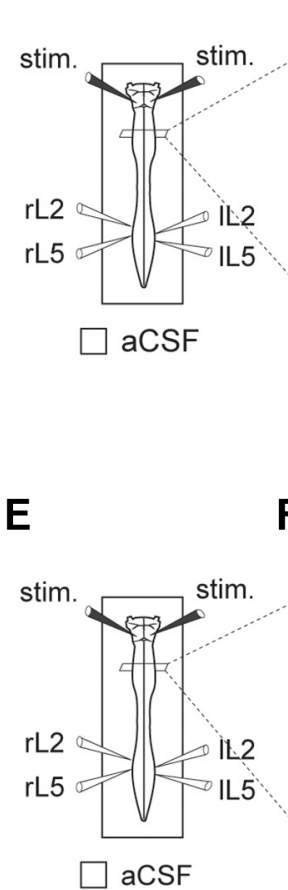

$\mathrm{F}$

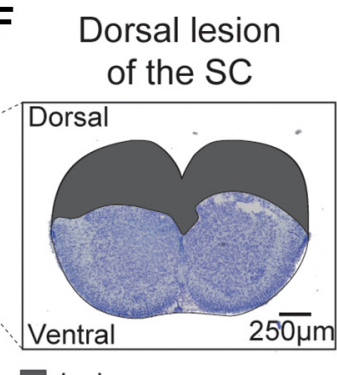

lesion

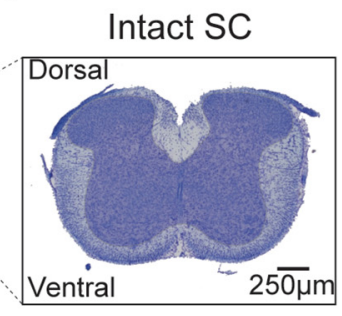

C

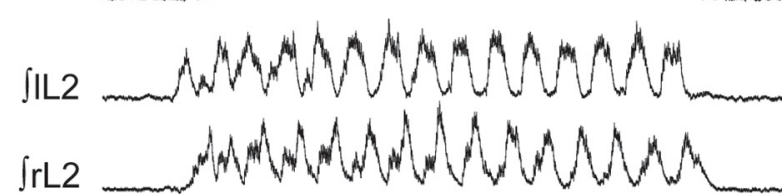

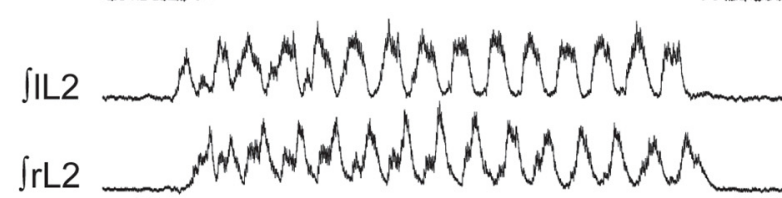

$\int \mathrm{rL} 5$

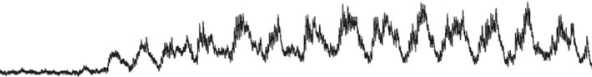

JIL5

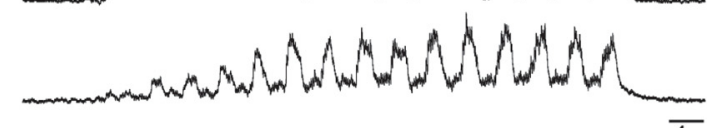

I.stim

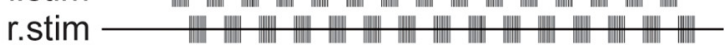

\section{G}

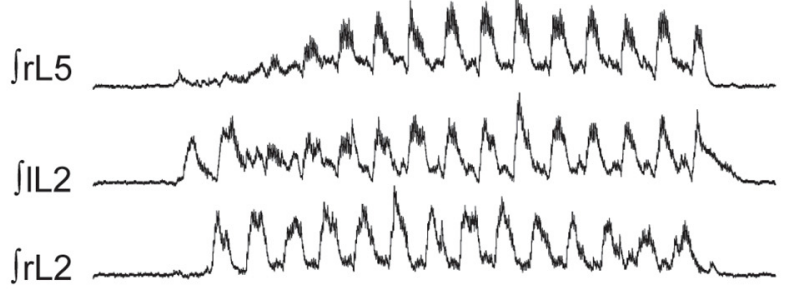

siL5

I.stim C

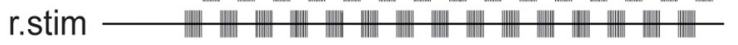

D

IL2 vs rL2

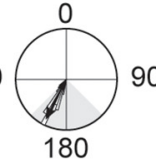

rL5 vs rL2

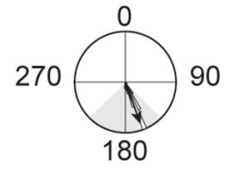

H

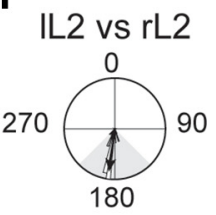

rL5 vs rL2

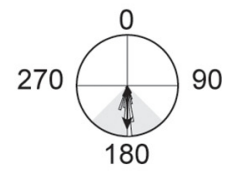

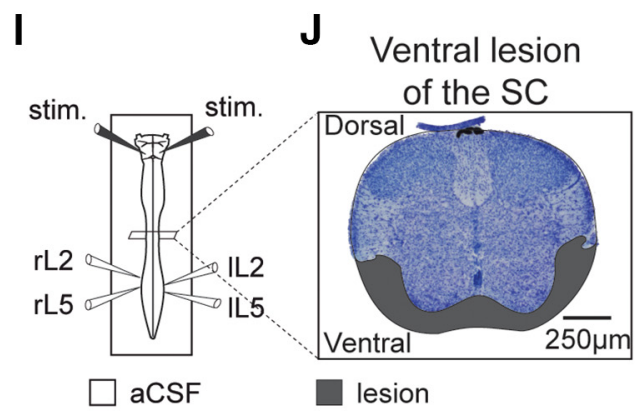

K

$\int \mathrm{rL5}$

$\int \mid \mathrm{L} 2$

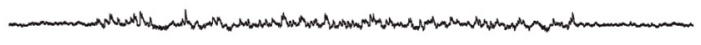

$\int \mathrm{rL} 2$

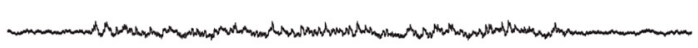

JIL5

I.stim

r.stim

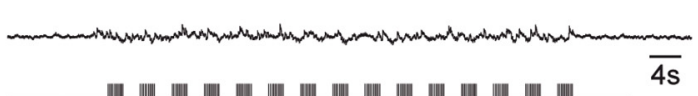

$\overline{4 s}$

Figure 8. The activation of fictive locomotion by RSP is mediated by the ventral funiculi. $\boldsymbol{A}$, Schematic of the experimental procedure for $\boldsymbol{B}-\boldsymbol{D}$. $\boldsymbol{B}$, Coronal slice of the intact spinal cord illustrating the proportions of gray and white matters colored in dark and pale purple, respectively. $C$, Integrated activities of lumbar ventral roots during an episode of fictive locomotion induced by a symmetrical RSP. D, Circular plots from the same recording illustrating phase alternation both between bilateral L2 (top) and ipsilateral L5 and L2 (bottom) activities. $\boldsymbol{E}-\boldsymbol{K}$, Same representations as in $\boldsymbol{A}-\boldsymbol{D}$, but with the spinal cord lesioned (dark gray areas) either dorsally $(\boldsymbol{E}-\boldsymbol{H})$ or ventrally $(\boldsymbol{I}-\boldsymbol{K})$. SC, Spinal cord.

that the RSP exerts most of its action through the activation of glutamatergic reticulospinal neurons, although a limited contribution of other descending pathways cannot be excluded.

\section{Contribution of rostral lumbar segments to pattern formation}

Reticulospinal neurons are known to project both to lumbar CPG circuitry and to motoneuronal levels (Jankowska et al., 2005; Hammar et al., 2007; Szokol et al., 2008; 2011; Szokol and Perreault, 2009). To determine whether RSP-induced fictive locomotion requires the involvement of the lumbar CPG or results from a direct activation of hindlimb motoneurons, we devised two series of experiments. In the first one, we used spinal cord preparations $(n=6$; Fig. $10 A-D)$ in which synaptic transmission was then suppressed from the low thoracic (Th11) through to midlumbar segments (L3) by the selective perfusion of calcium- free aCSF over this restricted cord region (Fig. 10E). Following the resultant silencing of the higher lumbar segments where the lumbar CPGs are located, as expected, discharge of any sort could no longer be elicited at the L2 level in response to RSP stimulation (Fig. 10F-H). In contrast, the left and right L5 ventral roots could exhibit either tonic (two of six) or nonlocomotor bursting activity (four of six; Fig. 10H). However, in the latter cases, the amplitude of L5 bursting was dramatically decreased, and the otherwise strict phase relationship between the left and right sides was impaired compared to control. This alteration was confirmed by the significant decrease found in the coherence value between the left and right L5 ventral root activities (Fig. 10G). The washout of the calcium-free solution with normal saline reversed these effects (Fig. 10J-L).

In a complementary series of experiments, the lumbosacral segments were split at the midsagittal plane (down from Th10) to 
A

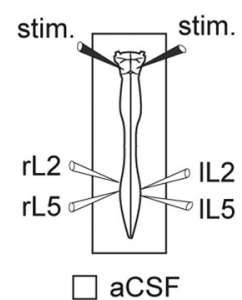

D

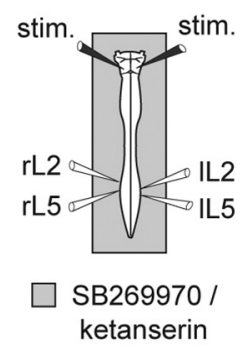

B JrL5 JIL2

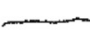

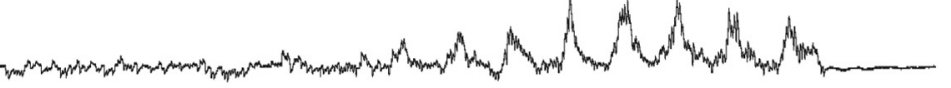

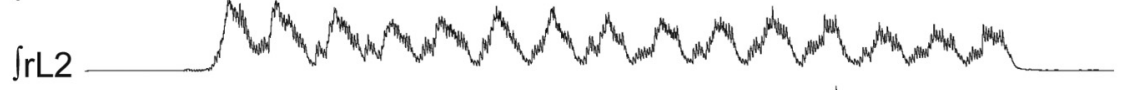
JIL5

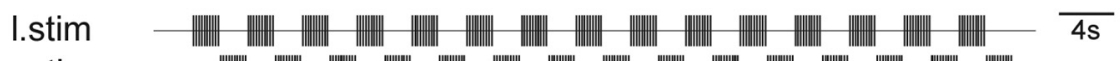
r.stim L.

E

$\int \mathrm{rL5}$

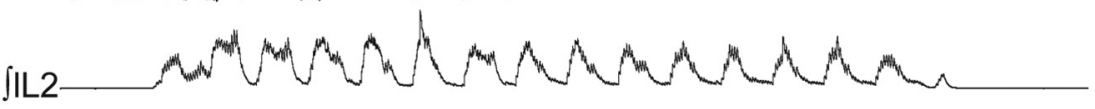

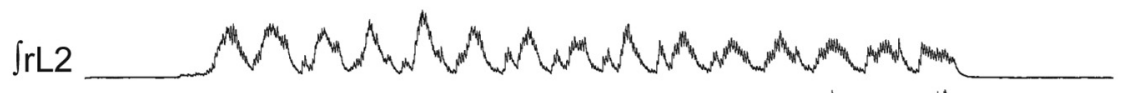
JIL5 I.stim C
C

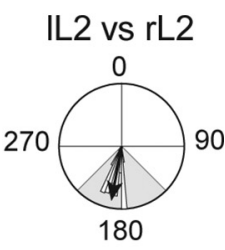

rL5 vs rL2

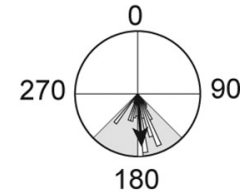

$\mathbf{F}$

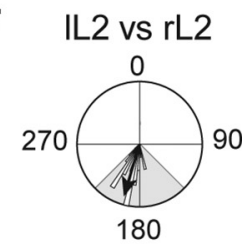

rL5 vs rL2

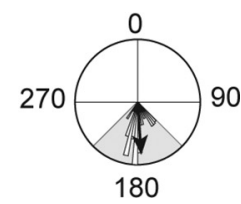

Figure 9. Blockade of $5-\mathrm{HT}_{2 \mathrm{~A}}$ and $5-\mathrm{HT}_{7}$ receptors does not affect RSP-induced locomotor-like activity. $\boldsymbol{A}$, Schematic of experimental procedure. $\boldsymbol{B}$, Integrated activities of lumbar ventral roots during an episode of fictive locomotion evoked by the RSP. C, Circular plots from the same recording showing phase alternation between both bilateral L2 (top) and ipsilateral L5 and L2 (bottom) activities. D-F, Episode of RSP-induced fictive locomotion (with corresponding polar plots) in the same preparation in the presence of serotonergic 5-HT2A (ketanserin, $10 \mu \mathrm{M})$ and 5- $\mathrm{HT}_{7}(\mathrm{SB} 269970$, $10 \mu \mathrm{m})$ receptor antagonists.

interrupt the bilateral commissural communications between the left and right sides. A typical example of the overall procedure is presented in Figure 11 for one preparation. Before the lesion, the RSP invariably ( $n=12$ preparations) induced locomotor-like activity (Fig. 11A-C). Following the sagittal split, however (Fig. $11 D$ ), the RSP still triggered rhythmical activity (Fig. 11E), but one whose temporal organization no longer fulfilled all the temporal criteria of locomotor activity. In this example, the alternation between the right L5 and L2 bursting activities was lost (Fig. $11 F)$. Among the 12 preparations tested that all expressed locomotor-like activity before the sagittal split, only one still expressed a locomotor-like pattern following the split (Fig. 11G). In the remaining preparations, except 2 that no longer expressed any rhythmic activity following the split, the loss of locomotion was primarily due to a loss of rhythmical activities of L5 ventral roots or to an inappropriate phasing of L5 bursting activities related to L2 (Fig. $11 H)$. Altogether, these data indicate that to elicit locomotor-like activity, the RSP does not act primarily via a direct action at the motoneuronal level, but rather through the recruitment of the lumbar locomotor CPGs.

\section{Discussion}

In the present work, we first show from isolated neonatal rat brainstem-spinal cord preparations (P0-P2) that a fraction of antidromically identified medullary reticulospinal neurons exhibit membrane potential oscillations phase locked to the locomotor output locally evoked at the spinal cord level. Because of the absence of sensory feedback in these preparations, this means that, as early as at birth in the rat, the spinal locomotor networks already convey an afferent copy of their ongoing operation at the brainstem level. Second, we show that rhythmic electrical stimulation of the ventral surface of the brainstem bilaterally is an efficient method to trigger episodes of locomotor-like activity. The protocol allows fine tuning of both the period and the pattern of the locomotor output. Finally, our lesion experiments show that the efficiency of the stimulation method relies on the integrity of the descending pathways located in the ventral quadrant of the spinal cord, without requiring the activation of the descending serotonergic pathways.

\section{Reticulospinal neurons' membrane potential oscillations during locomotion}

In this study, intracellular recordings were obtained from antidromically identified RSNs with axons projecting at least to the midthoracic level (Kuypers and Maisky, 1977; Tohyama et al., 1979; Steeves and Jordan, 1980; Drew et al., 1986; Noga et al., 1991; Reed et al., 2008). At rest, none of the cells exhibited any discharge activity. However, during the phamacological activation of the spinal locomotor network by the cocktail NMDA/ serotonin (Cazalets et al., 1992), all cells depolarized and discharged action potentials. The discharge pattern of activity allowed us to classify RSNs as tonically or rhythmically active during episodes of fictive locomotion. Half of the rhythmically active RSNs fired action potential during the ipsilateral flexorlike (L2 segment) activity of the locomotor output recorded from the lumbar spinal cord, the other half during the contralateral flexor-like bursts of activity, which in our preparation also corresponded to the ipsilateral extensor-like activity (Kiehn and Kjaerulff, 1996). Overall, the RSNs' patterns of activity recorded ex vivo at birth in the rat strikingly resemble the patterns of activ- 
A

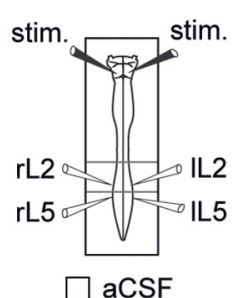

E
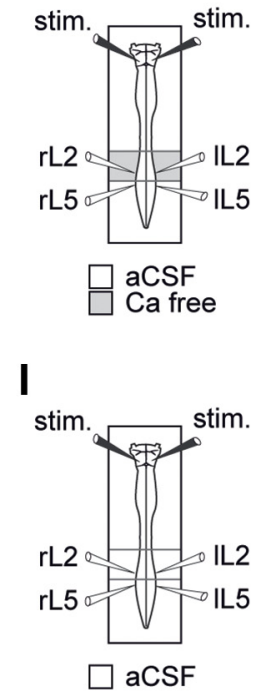

B

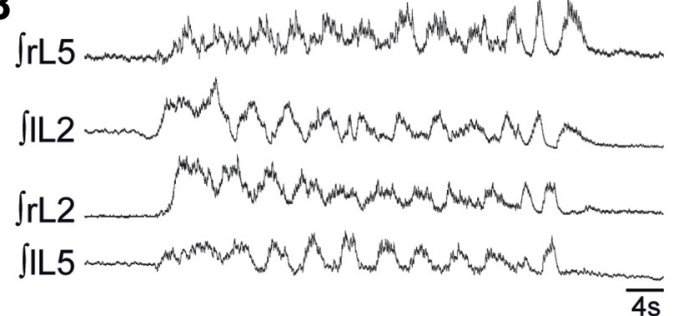

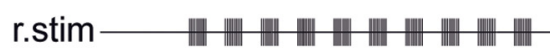

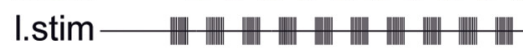

$\mathbf{F}$
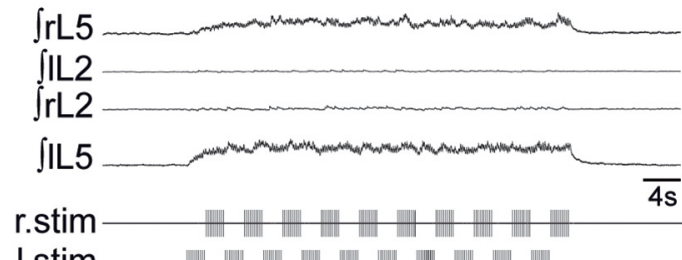

I.stim

J

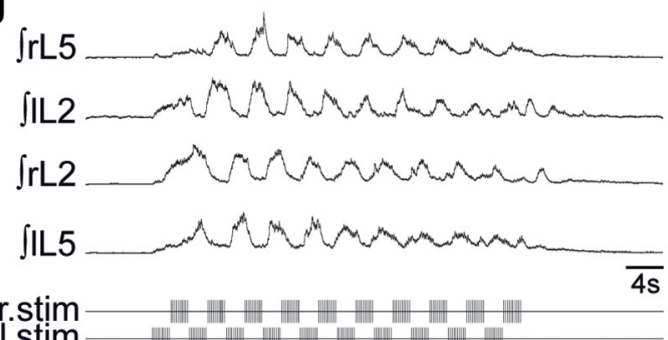

C

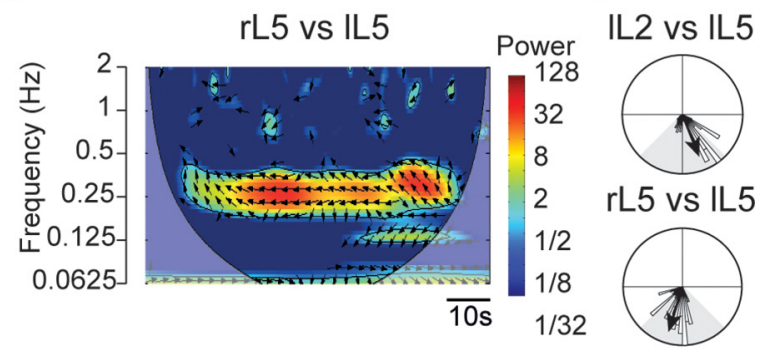

G
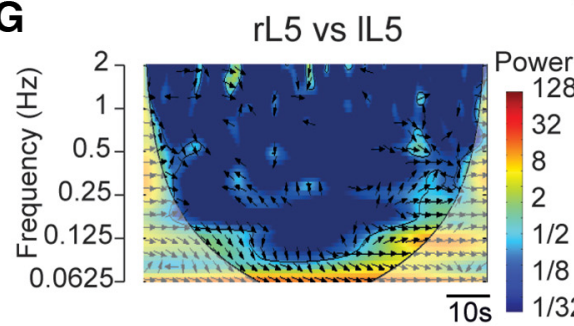

H

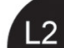

K
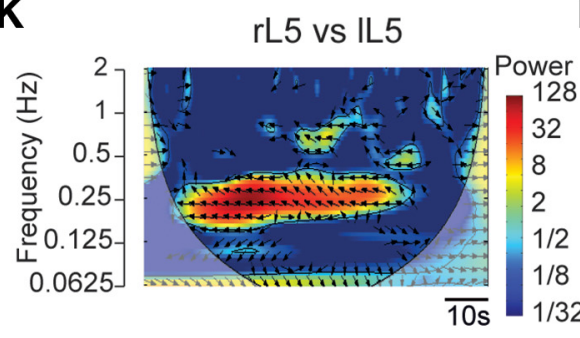

No activity

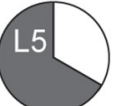

Non Loco.

Tonic

L IL2 vs IL5

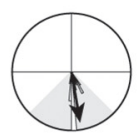

rL5 vs IL5

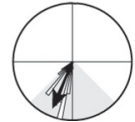

Figure 10. RSP-induced fictive locomotion depends on the synaptic integrity of the lumbar CPG. $A$, Schematic of experimental procedures. $\boldsymbol{B}$, Integrated activities of lumbar ventral roots during an episode of fictive locomotion induced by the RSP. C, Wavelet coherence analysis of the recording in $\boldsymbol{B}$ showing a high coherence between bilateral $L 5$ lumbar activities. $\boldsymbol{D}$, Circular plots from the same recording indicating phase alternation between ipsilateral L2/L5 (top) and bilateral L5 (bottom) activities. E-G, Calcium-free aCSF applied selectively to the rostral lumbar segments (Th11-L3; E) of the same preparation abolishes RSP-induced rhythmic locomotor-like activity $(\boldsymbol{F}, \mathbf{G})$. $\boldsymbol{H}$, Proportions of preparations $(n=6)$ in which L2 (top) and L5 (bottom) expressed tonic (unshaded; L5; 2 of 6), burst-like (dark gray; L5; 4 of 6), and no activity (light gray; L2; 6 of 6) during rostrolumbar application of calcium-free aCSF. J-L, Recovery of RSP-induced locomotor-like activity ( $\boldsymbol{K}$ ), with a strong coherence of left and right $L 5$ bursts $(\boldsymbol{L})$ and phase alternation after washout of the calcium-free solution $(\boldsymbol{J})$.

ity recorded from pontomedullary RSNs during locomotion in the cat (Shimamura et al., 1982, 1985; Shimamura and Kogure, 1983; Drew et al., 1986; Perreault et al., 1993; Matsuyama and Drew, 2000) and the lamprey (Kasicki and Grillner, 1986; Dubuc and Grillner, 1989; Kasicki et al., 1989; Deliagina et al., 2000). These data also provide the first evidence that an ascending efferent copy of the spinal locomotor operation is already present at birth.

\section{Brainstem activation of the spinal locomotor network}

The reticulospinal system is a key relay of descending locomotor commands coming from the MLR (Shik et al., 1966; Skinner and Garcia-Rill, 1984; Steeves and Jordan, 1984). In neonatal rodents, several descending stimulation paradigms (pharmacological, Smith et al., 1988; electrical, Magnuson and Trinder, 1997; Zaporozhets et al., 2004; Cowley et al., 2010; optogenetic, Hägglund et al., 2010) have been used to trigger fictive locomotion in isolated brainstem-spinal cord preparations. Overall, these approaches are based on continuous, unpatterned activations of the MLR or the reticular formation. However, it is well established that part of the reticular neurons exhibit rhythmical firing patterns during locomotion (Orlovskil., 1970; Shimamura et al., 1982, 1985; Drew et al., 1986; Kasicki and Grillner, 1986; Garcia-
Rill et al., 2001). Here, we provide evidence that rhythmically activating the descending pathways at the level of the caudal ventral surface of the brainstem to mimic the bilaterally alternating phasic activity of reticulospinal neurons during locomotion reliably activates the spinal locomotor networks. The stimulation parameters, including the intensity (Zaporozhets et al., 2004), pulse duration, and intraburst frequency (Garcia-Rill and Skinner, 1987), were all in the range of that used for tonic stimulation in neonatal and adult rats.

\section{Brainstem pathway activation}

Zaporozhets et al. (2004) showed that during unilateral tonic brainstem stimulation, stimulation of the axons lying within the brainstem was sufficient to trigger locomotor episodes, although a concomitant contribution of an excitation of the neuronal cell bodies could not be completely ruled out. In light of the similarities of our electrical macrostimulation methods, it is very likely that the same mechanisms are in action. However, one major difference between our methods is the brainstem regions that can be stimulated to activate the spinal locomotor network. Tonic unilateral stimulation triggers locomotion when delivered almost anywhere in the medial part of the medulla and pons. In contrast, the patterned electrical stimulation protocol we devised is most 


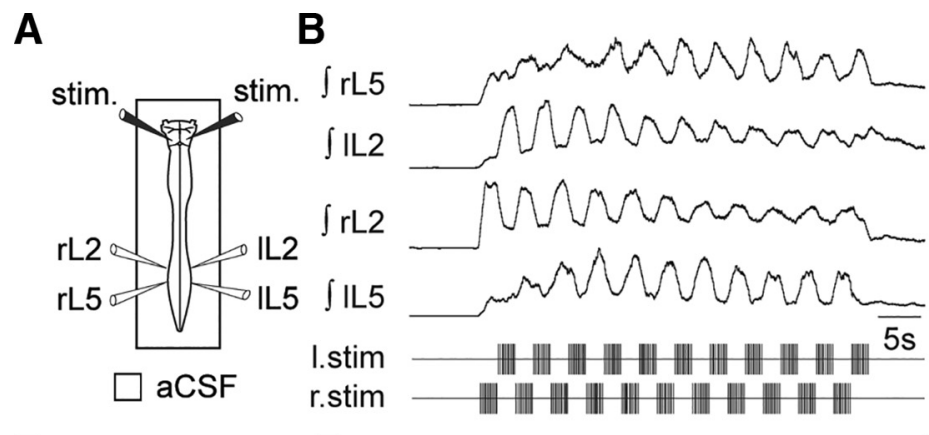

C

IL2 / rL2

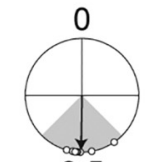

IL5 / rL2 $0.5 \mathrm{rL} 5 / \mathrm{rL} 2$

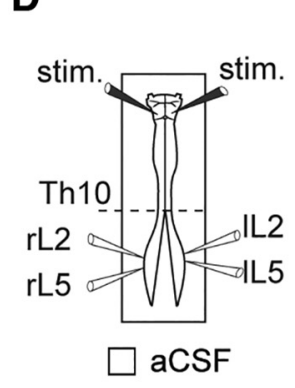

E

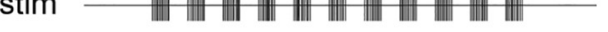
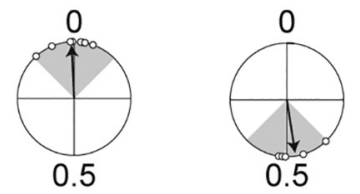

$\mathbf{F}$

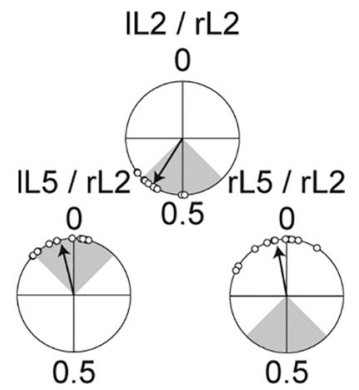

G

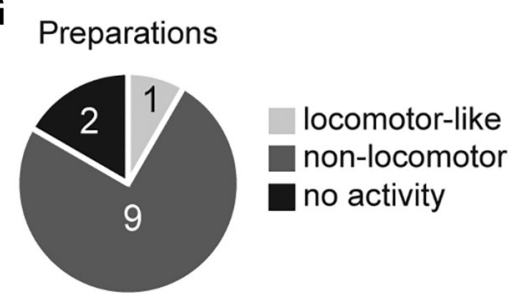

$H$

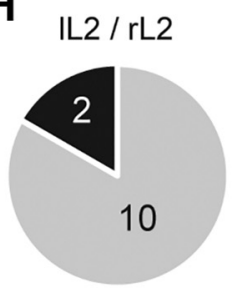

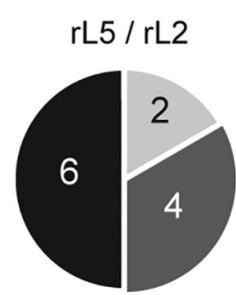

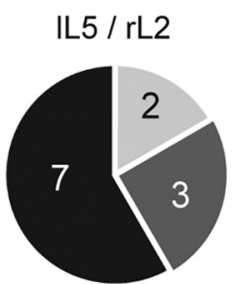

Preparations

Figure 11. Lumbar commissural pathways are required to set the locomotor timing of extensor-related bursts during the RSP. $\boldsymbol{A}$, Schematic of experimental procedure. $\boldsymbol{B}$, Integrated activities of lumbar ventral roots induced by the RSP in the control condition. C, Circular plots from the same recording indicating the phase relationships between IL2 and rL2 (top) and between right and left $L 5$ and rL2 (bottom) activities. The location of the mean vectors (black) in the gray-shaded areas indicates the locomotor nature of the expressed pattern of activity. $\boldsymbol{D}$, Schematic of experimental procedure showing the midsagittal split of the lumbosacral spinal cord (from Th10). $\boldsymbol{E}$, Integrated activities of lumbar ventral roots induced by the RSP from the same preparation as in $\boldsymbol{B}$ after the split. $\boldsymbol{F}$, Same as C after the sagittal split. Note that although the RSP still triggers a rhythmical activity, the loss of alternation between rL5 and rL2 activities highlights the loss of locomotor-like activity. $G$, Circular chart indicating the proportions of preparations $(n=12)$ that expressed locomotor-like (1 of 12), non-locomotor-like ( 9 of 12$)$, and no activity (2 of 12$)$ following the sagittal transection. $\boldsymbol{H}$, Proportions of preparations that displayed locomotor-like phasing between pairs of ventral root activities. Note that most of time the bilateral L2 alternation was maintained (10 of 12 ), while the locomotor phasing between $\mathrm{L} 5$ and $\mathrm{L} 2$ activities (10 of 12), was lost after the split.

efficient when delivered in the caudal ventral area of the brainstem encompassing the lateral reticular nucleus and lateral paragigantocellular nucleus, both involved in locomotor control.

Although serotonin is a well-established neuromodulator of locomotor spinal networks, our stimulation method does not require the activation of descending serotonergic axons from the LPGi or surrounding parapyramidal region (Liu and Jordan, 2005), as the pharmacological blockade of the $5-\mathrm{HT}_{2 \mathrm{~A}}$ and $5-\mathrm{HT}_{7}$ serotonin receptors did not prevent the generation of locomotor episodes. Thus, the RSP mechanism is not supported by the neuromodulatory action of serotonin on the spinal locomotor network. This is in line with recent optogenetic work showing that activation of glutamatergic neurons only within the LPGi triggers episodes of locomotion in vivo (Capelli et al., 2017). Because ascending and descending pathways, including propriospinal tracts, are critical for the initiation of locomotion in our preparation (Cowley et al., 2010; Etlin et al., 2010), we also restricted the main pathway relaying RSP control to the ventral part of the spinal cord. Indeed, as observed in the cat (Noga et al., 1991), dorsal hemisections of the spinal cord at the high thoracic level, interrupting the lateral corticospinal tracts, did not block loco- motion. In contrast, ventral hemisection prevented the expression of locomotor activities, which is in favor of a well-established pivotal role of the reticulospinal fibers. However, we cannot completely exclude a contribution of other ventrally located communication tracks, including the ventral vestibular (Kasumacic et al., 2010), the ventral corticospinal pathways, and the propriospinal tracts that relay intersegmental information.

\section{Steering of locomotor activity}

The MLR and reticular formation linearly control the speed and gait of locomotion (Shik et al., 1966; Skinner and Garcia-Rill, 1984; Garcia-Rill and Skinner, 1987; Atsuta et al., 1990; Zaporozhets et al., 2004). Although the locomotor frequency is correlated to the frequency/amplitude of stimulation, it cannot be easily set to a predetermined value. In contrast, bilateral patterned stimulation allows a fine tuning of the locomotor period, without any manipulation of the stimulation intensity or intratrain frequencies. In light of the location of our stimulation electrodes over the caudoventral area of the brainstem, our method is likely to activate the lateral paragigantocellular nuclei, which were recently implicated in the control of locomotor activity in 
the mouse (Capelli et al., 2017). Optogenetic activation of glutamatergic LPGi neurons initiates locomotion and allows a quite linear control of the locomotor speed. Conversely, ablation of these neurons narrows the range of locomotor speeds toward slow values. However, whether this nucleus is differentially targeted by the MLR nuclei that control slow and high-speed locomotion (Caggiano et al., 2018) remains to be formally elucidated.

Modeling and computational studies of the lamprey locomotor system revealed the operational advantage of phasic oscillations in RSNs for the gating of descending steering commands (Grillner et al., 2007; Kozlov et al., 2014). For instance, the phasic modulation of reticulospinal cells acts as a filter that determines the timing at which a visual tectal steering command will be integrated with the ongoing locomotor activity. This ensures the initiation of a lateral turn only during a permissive phase of the locomotor cycle. As a result, a turning command results in asymmetrical discharge activity of the left and right reticulospinal cells (Wannier et al., 1998; Deliagina et al., 2000) that triggers asymmetrical activity of the left and right locomotor outputs (Fagerstedt and Ullén, 2001). Here we show for a quadruped that unbalancing the timing of left and right descending locomotor commands creates a bias in the locomotor output. In most cases, the duration of the flexor-like output was perfectly determined by the duration of the ipsilateral side of the brainstem. Given the flexor/extensor-like alternation rule during locomotion, the duration of the extensor phase on one side is then fixed by the duration of the contralateral brainstem stimulation. However, when the left/right asymmetry was exaggerated, for instance, when the duration on one side was set to $1 \mathrm{~s}$ and that on the opposite side was set to $3 \mathrm{~s}$, the duration of the corresponding locomotor phases could escape so that the asymmetry, albeit clearly present, was less pronounced. This indicates the descending instructions cannot completely overcome the operations of the locomotor CPG. Thus, it is very likely that the locomotor CPG filters the descending information (Drew, 1991; Perreault et al., 1994) as it does for the sensory feedbacks (Juvin et al., 2012). Indeed, direction change is likely to result from the integration by the spinal locomotor networks of both the descending command and sensory afferent information that also regulates phase transitions and left/right coupling during locomotion (Musienko et al., 2012; Frigon et al., 2017). Here we show that abolishing commissural communication at the lumbar CPG level disrupts the RSP's capacity to trigger fictive locomotion. Further work will be needed to define more precisely the role of lamina VIII commissural interneurons known to receive monosynaptic and polysynaptic inputs from the brainstem (Jankowska et al., 2003, 2005), and that potentially belong to V0v, V0d, and V3 neuronal subpopulations involved in left/right couplings (Zhang et al., 2008; Talpalar et al., 2013; Bellardita and Kiehn, 2015).

\section{Conclusion}

In conclusion, manipulating the temporal organization of the spinally descending flow of information at the ventral brainstem level is very efficient to finely tune the operation of the spinal locomotor network. Together with data obtained previously on swimming lamprey, our study indicates that the reticular formation's contribution to the control of locomotor speed and direction is at least partly conserved in vertebrates. This will certainly open new perspectives to unravel the spinal neuronal substrate of the descending control in mammals.

\section{References}

Antri M, Fénelon K, Dubuc R (2009) The contribution of synaptic inputs to sustained depolarizations in reticulospinal neurons. J Neurosci 29:1140 1151. CrossRef Medline

Armstrong DM (1986) Supraspinal contributions to the initiation and control of locomotion in the cat. Prog Neurobiol 26:273-361. CrossRef Medline

Atsuta Y, Garcia-Rill E, Skinner RD (1990) Characteristics of electrically induced locomotion in rat in vitro brain stem-spinal cord preparation. J Neurophysiol 64:727-735. CrossRef Medline

Ballion B, Morin D, Viala D (2001) Forelimb locomotor generators and quadrupedal locomotion in the neonatal rat. Eur J Neurosci 14:17271738. CrossRef Medline

Barthélemy D, Leblond H, Rossignol S (2007) Characteristics and mechanisms of locomotion induced by intraspinal microstimulation and dorsal root stimulation in spinal cats. J Neurophysiol 97:1986-2000. CrossRef Medline

Beliez L, Barrière G, Bertrand SS, Cazalets JR (2015) Origin of thoracic spinal network activity during locomotor-like activity in the neonatal rat. J Neurosci 35:6117-6130. CrossRef Medline

Bellardita C, Kiehn O (2015) Phenotypic characterization of speedassociated gait changes in mice reveals modular organization of locomotor networks. Curr Biol 25:1426-1436. CrossRef Medline

Berens P (2009) CircStat: a MATLAB toolbox for circular statistics. J Statist Software 31:1-21.

Cabaj AM, Majczyński H, Couto E, Gardiner PF, Stecina K, Sławińska U, Jordan LM (2017) Serotonin controls initiation of locomotion and afferent modulation of coordination via 5-HT7 receptors in adult rats. J Physiol 595:301-320. CrossRef Medline

Caggiano V, Leiras R, Goñi-Erro H, Masini D, Bellardita C, Bouvier J, Caldeira V, Fisone G, Kiehn O (2018) Midbrain circuits that set locomotor speed and gait selection. Nature 553:455-460. CrossRef Medline

Capelli P, Pivetta C, Soledad Esposito M, Arber S (2017) Locomotor speed control circuits in the caudal brainstem. Nature 551:373-377. Medline

Cazalets JR, Sqalli-Houssaini Y, Clarac F (1992) Activation of the central pattern generators for locomotion by serotonin and excitatory amino acids in neonatal rat. J Physiol 455:187-204. CrossRef Medline

Cazalets JR, Borde M, Clarac F (1995) Localization and organization of the central pattern generator for hindlimb locomotion in newborn rat. J Neurosci 15:4943-4951. CrossRef Medline

Cowley KC, Zaporozhets E, Schmidt BJ (2010) Propriospinal transmission of the locomotor command signal in the neonatal rat. Ann N Y Acad Sci 1198:42-53. CrossRef

Deliagina TG, Zelenin PV, Fagerstedt P, Grillner S, Orlovsky GN (2000) Activity of reticulospinal neurons during locomotion in the freely behaving lamprey. J Neurophysiol 83:853-863. CrossRef Medline

Drew T (1991) Functional organization within the medullary reticular formation of the intact unanesthetized cat. III. Microstimulation during locomotion. J Neurophysiol 66:919-938. CrossRef Medline

Drew T, Dubuc R, Rossignol S (1986) Discharge patterns of reticulospinal and other reticular neurons in chronic, unrestrained cats walking on a treadmill. J Neurophysiol 55:375-401. CrossRef Medline

Dubuc R, Grillner S (1989) The role of spinal cord inputs in modulating the activity of reticulospinal neurons during fictive locomotion in the lamprey. Brain Res 483:196-200. CrossRef Medline

Etlin A, Blivis D, Ben-Zwi M, Lev-Tov A (2010) Long and short multifunicular projections of sacral neurons are activated by sensory input to produce locomotor activity in the absence of supraspinal control. J Neurosci 30:10324-10336. CrossRef Medline

Fagerstedt P, Ullén F (2001) Lateral turns in the lamprey. I. Patterns of motoneuron activity. J Neurophysiol 86:2246-2256. CrossRef Medline

Fagerstedt P, Orlovsky GN, Deliagina TG, Grillner S, Ullén F (2001) Lateral turns in the lamprey. II. activity of reticulospinal neurons during the generation of fictive turns. J Neurophysiol 86:2257-2265. CrossRef Medline

Frigon A, Desrochers É, Thibaudier Y, Hurteau MF, Dambreville C (2017) Left-right coordination from simple to extreme conditions during splitbelt locomotion in the chronic spinal adult cat. J Physiol 595:341-361. CrossRef Medline

Garcia-Rill E, Skinner RD (1987) The mesencephalic locomotor region. I. activation of a medullary projection site. Brain Res 411:1-12. CrossRef Medline

Garcia-Rill E, Houser CR, Skinner RD, Smith W, Woodward DJ (1987) 
Locomotion-inducing sites in the vicinity of the pedunculopontine nucleus. Brain Res Bull 18:731-738. CrossRef Medline

Garcia-Rill E, Skinner RD, Miyazato H, Homma Y (2001) Pedunculopontine stimulation induces prolonged activation of pontine reticular neurons. Neuroscience 104:455-465. CrossRef Medline

Grillner S, Kozlov A, Dario P, Stefanini C, Menciassi A, Lansner A, Hellgren Kotaleski J (2007) Modeling a vertebrate motor system: pattern generation, steering and control of body orientation. Prog Brain Res 165:221234. CrossRef Medline

Grinsted A, Moore JC, Jevrejeva S (2004) Application of the cross wavelet transform and wavelet coherence to geophysical time series. Nonlinear Processes in Geophysics, European Geosciences Union 11:561-566. CrossRef

Hägglund M, Borgius L, Dougherty KJ, Kiehn O (2010) Activation of groups of excitatory neurons in the mammalian spinal cord or hindbrain evokes locomotion. Nat Neurosci 13:246-252. CrossRef Medline

Hammar I, Stecina K, Jankowska E (2007) Differential modulation by monoamine membrane receptor agonists of reticulospinal input to lamina VIII feline spinal commissural interneurons. Eur J Neurosci 26:12051212. CrossRef Medline

Jankowska E, Hammar I, Slawinska U, Maleszak K, Edgley SA (2003) Neuronal basis of crossed actions from the reticular formation on feline hindlimb motoneurons. J Neurosci 23:1867-1878. CrossRef Medline

Jankowska E, Edgley SA, Krutki P, Hammar I (2005) Functional differentiation and organization of feline midlumbar commissural interneurones. J Physiol 565:645-658. CrossRef Medline

Jordan LM (1998) Initiation of locomotion in mammals. Ann N Y Acad Sci 860:83-93. CrossRef

Jordan LM, Liu J, Hedlund PB, Akay T, Pearson KG (2008) Descending command systems for the initiation of locomotion in mammals. Brain Res Brain Res Rev 57:183-191. CrossRef

Juvin L, Simmers J, Morin D (2005) Propriospinal circuitry underlying interlimb coordination in mammalian quadrupedal locomotion. J Neurosci 25:6025-6035. CrossRef Medline

Juvin L, Le Gal JP, Simmers J, Morin D (2012) Cervicolumbar coordination in mammalian quadrupedal locomotion: role of spinal thoracic circuitry and limb sensory inputs. J Neurosci 32:953-965. CrossRef Medline

Karayannidou A, Zelenin PV, Orlovsky GN, Deliagina TG (2007) Responses of reticulospinal neurons in the lamprey to lateral turns. J Neurophysiol 97:512-521. CrossRef Medline

Kasicki S, Grillner S (1986) Müller cells and other reticulospinal neurones are phasically active during fictive locomotion in the isolated nervous system of the lamprey. Neurosci Lett 69:239-243. CrossRef Medline

Kasicki S, Grillner S, Ohta Y, Dubuc R, Brodin L (1989) Phasic modulation of reticulospinal neurones during fictive locomotion and other types of spinal motor activity in lamprey. Brain Res 484:203-216. CrossRef Medline

Kasumacic N, Glover JC, Perreault MC (2010) Segmental patterns of vestibular-mediated synaptic inputs to axial and limb motoneurons in the neonatal mouse assessed by optical recording. J Physiol 588:4905-4925. CrossRef Medline

Kiehn O, Kjaerulff O (1996) Spatiotemporal characteristics of 5-HT and dopamine-induced rhythmic hindlimb activity in the in vitro neonatal rat. J Neurophysiol 75:1472-1482. CrossRef Medline

Kozlov AK, Kardamakis AA, Hellgren Kotaleski J, Grillner S (2014) Gating of steering signals through phasic modulation of reticulospinal neurons during locomotion. Proc Natl Acad Sci U S A 111:3591-3596. CrossRef Medline

Kuypers HG, Maisky VA (1977) Funicular trajectories of descending brain stem pathways in cat. Brain Res 136:159-165. CrossRef Medline

Liu J, Jordan LM (2005) Stimulation of the parapyramidal region of the neonatal rat brain stem produces locomotor-like activity involving spinal 5-HT7 and 5-HT2A receptors. J Neurophysiol 94:1392-1404. CrossRef Medline

Liu Q, Wong-Riley MT (2010) Postnatal changes in tryptophan hydroxylase and serotonin transporter immunoreactivity in multiple brainstem nuclei of the rat: implications for a sensitive period. J Comp Neurol 518:10821097. CrossRef Medline

Magnuson DS, Trinder TC (1997) Locomotor rhythm evoked by ventrolateral funiculus stimulation in the neonatal rat spinal cord in vitro. J Neurophysiol 77:200-206. CrossRef Medline

Marcoux J, Rossignol S (2000) Initiating or blocking locomotion in spinal cats by applying noradrenergic drugs to restricted lumbar spinal segments. J Neurosci 20:8577-8585. CrossRef Medline

Matsuyama K, Drew T (1997) Organization of the projections from the pericruciate cortex to the pontomedullary brainstem of the cat: a study using the anterograde tracer phaseolus vulgaris-leucoagglutinin. J Comp Neurol 389:617-641. CrossRef Medline

Matsuyama K, Drew T (2000) Vestibulospinal and reticulospinal neuronal activity during locomotion in the intact cat. I. Walking on a level surface. J Neurophysiol 84:2237-2256. CrossRef Medline

Matsuyama K, Mori F, Nakajima K, Drew T, Aoki M, Mori S (2004) Locomotor role of the corticoreticular-reticulospinal-spinal interneuronal system. Prog Brain Res 143:239-249. CrossRef Medline

McClellan AD, Grillner S (1984) Activation of "fictive swimming" by electrical microstimulation of brainstem locomotor regions in an in vitro preparation of the lamprey central nervous system. Brain Res 300:357361. CrossRef Medline

Mor Y, Lev-Tov A (2007) Analysis of rhythmic patterns produced by spinal neural networks. J Neurophysiol 98:2807-2817. CrossRef Medline

Musienko PE, Zelenin PV, Lyalka VF, Gerasimenko YP, Orlovsky GN, Deliagina TG (2012) Spinal and supraspinal control of the direction of stepping during locomotion. J Neurosci 32:17442-17453. CrossRef Medline

Noga BR, Kriellaars DJ, Jordan LM (1991) The effect of selective brainstem or spinal cord lesions on treadmill locomotion evoked by stimulation of the mesencephalic or pontomedullary locomotor regions. J Neurosci 11: 1691-1700. CrossRef Medline

Noga BR, Kriellaars DJ, Brownstone RM, Jordan LM (2003) Mechanism for activation of locomotor centers in the spinal cord by stimulation of the mesencephalic locomotor region. J Neurophysiol 90:1464-1478. CrossRef Medline

Orlovskiū GN (1970) Work of reticulo-spinal neurons during locomotion (in Russian). Biofizika 15:728-737. Medline

Paxinos G, Ashwell KWS (2018) Atlas of the developing rat nervous system. London, United Kingdom; San Diego, CA: Academic Press.

Pearlstein E, Ben Mabrouk F, Pflieger JF, Vinay L (2005) Serotonin refines the locomotor-related alternations in the in vitro neonatal rat spinal cord. Eur J Neurosci 21:1338-1346. CrossRef Medline

Perreault MC, Drew T, Rossignol S (1993) Activity of medullary reticulospinal neurons during fictive locomotion. J Neurophysiol 69:2232-2247. CrossRef Medline

Perreault MC, Rossignol S, Drew T (1994) Microstimulation of the medullary reticular formation during fictive locomotion. J Neurophysiol 71: 229-245. CrossRef Medline

Reed WR, Shum-Siu A, Magnuson DS (2008) Reticulospinal pathways in the ventrolateral funiculus with terminations in the cervical and lumbar enlargements of the adult rat spinal cord. Neuroscience 151:505-517. CrossRef Medline

Rossignol S (1996) Neural control of stereotypic limb movements. In: Handbook of physiology, Sec 12, Regulation and integration of multiple systems (Rowell LB, Sheperd JT, eds), pp 173-216. CrossRef

Saitoh K, Ménard A, Grillner S (2007) Tectal control of locomotion, steering, and eye movements in lamprey. J Neurophysiol 97:3093-3108. CrossRef Medline

Shik ML, Severin FV, Orlovskiı̌ GN (1966) Control of walking and running by means of electric stimulation of the midbrain (in Russian). Biofizika 11:659-666. Medline

Shimamura M, Kogure I (1983) Discharge patterns of reticulospinal neurons corresponding with quadrupedal leg movements in thalamic cats. Brain Res 260:27-34. CrossRef Medline

Shimamura M, Kogure I, Wada S (1982) Reticular neuron activities associated with locomotion in thalamic cats. Brain Res 231:51-62. CrossRef Medline

Shimamura M, Fuwa T, Kogure I (1985) Burst discharges of pontine reticular neurons in relation to forelimb stepping of thalamic and high spinal cats. Brain Res 346:363-367. CrossRef Medline

Skinner RD, Garcia-Rill E (1984) The mesencephalic locomotor region (MLR) in the rat. Brain Res 323:385-389. CrossRef Medline

Smith JC, Feldman JL, Schmidt BJ (1988) Neural mechanisms generating locomotion studied in mammalian brain stem-spinal cord in vitro. FASEB J 2:2283-2288. CrossRef Medline

Steeves JD, Jordan LM (1980) Localization of a descending pathway in the spinal cord which is necessary for controlled treadmill locomotion. Neurosci Lett 20:283-288. CrossRef Medline 
Steeves JD, Jordan LM (1984) Autoradiographic demonstration of the projections from the mesencephalic locomotor region. Brain Res 307:263276. CrossRef Medline

Swanson LW (1992) Brain maps: structure of the rat brain. Amsterdam: Elsevier.

Szokol K, Perreault MC (2009) Imaging synaptically mediated responses produced by brainstem inputs onto identified spinal neurons in the neonatal mouse. J Neurosci Methods 180:1-8. CrossRef Medline

Szokol K, Glover JC, Perreault MC (2008) Differential origin of reticulospinal drive to motoneurons innervating trunk and hindlimb muscles in the mouse revealed by optical recording. J Physiol 586:5259-5276. CrossRef Medline

Szokol K, Glover JC, Perreault M-C (2011) Organization of functional synaptic connections between medullary reticulospinal neurons and lumbar descending commissural interneurons in the neonatal mouse. J Neurosci 31:4731-4742. CrossRef Medline

Talpalar AE, Bouvier J, Borgius L, Fortin G, Pierani A, Kiehn O (2013) Dualmode operation of neuronal networks involved in left-right alternation. Nature 500:85-88. CrossRef Medline
Tohyama M, Sakai K, Salvert D, Touret M, Jouvet M (1979) Spinal projections from the lower brain stem in the cat as demonstrated by the horseradish peroxidase technique. I. Origins of the reticulospinal tracts and their funicular trajectories. Brain Res 173:383-403. CrossRef Medline

Torrence C, Compo GP (1998) A practical guide to wavelet analysis. Bull Am Meteorol Soc 79:61-78. CrossRef

Wannier T, Deliagina TG, Orlovsky GN, Grillner S (1998) Differential effects of the reticulospinal system on locomotion in lamprey. J Neurophysiol 80:103-112. CrossRef Medline

Zaporozhets E, Cowley KC, Schmidt BJ (2004) A reliable technique for the induction of locomotor-like activity in the in vitro neonatal rat spinal cord using brainstem electrical stimulation. J Neurosci Methods 139:33-41. CrossRef Medline

Zhang Y, Narayan S, Geiman E, Lanuza GM, Velasquez T, Shanks B, Akay T, Dyck J, Pearson K, Gosgnach S, Fan CM, Goulding M (2008) V3 spinal neurons establish a robust and balanced locomotor rhythm during walking. Neuron 60:84-96. CrossRef Medline 